\title{
Liquid chromatographic resolution of natural and racemic Cinchona alkaloid analogues using strong cation- and zwitterion ion-exchange type stationary phases. Qualitative evaluation of stationary phase characteristics and mobile phase effects on stereoselectivity and retention
}

\author{
Attila Bajtai ${ }^{\mathrm{a}}$, István Ilisz ${ }^{\mathrm{a}, *}$, Antal Péter ${ }^{\mathrm{a}}$, Wolfgang Lindner ${ }^{\mathrm{b}, *}$ \\ a Institute of Pharmaceutical Analysis, Interdisciplinary Excellence Centre, University of Szeged, H-6720 Szeged, Somogyi utca 4, Hungary \\ ${ }^{\mathrm{b}}$ Department of Analytical Chemistry, University of Vienna, Währingerstrasse 38, 1090 Vienna, Austria
}

\section{A R T I C L E I N F O}

\section{Article history:}

Received 10 May 2019

Revised 22 August 2019

Accepted 23 August 2019

Available online 30 August 2019

\section{Keywords:}

HPLC

SFC

Cinchona alkaloids

Enantioseparation

\begin{abstract}
A B S T R A C T
Liquid chromatographic (LC) and subcritical fluid chromatographic (SFC) resolution of the basic natural and synthetic Cinchona alkaloid analogues has been studied. Focus has been placed on the employment of four enantiomerically structured chiral strong cation-exchangers and four chiral diastereoisomeric Cinchona alkaloid and cyclohexyl aminosulfonic acid-based zwitterionic ion-exchangers. Except for the novel, recently synthesized racemic quinine the other investigated pairs of basic analytes are diastereomeric, but often called "pseudoenantiomeric" compounds of quinine and quinidine, cinchonidine and cinchonine, 9epi-quinine and 9-epi-quinidine. As expected, the elution order of the resolved racemic quinine was reversed for all the eight investigated enantiomeric and (pseudo)enantiomeric pairs of chiral stationary phases, whereas this was not necessarily the case for the diastereomeric pairs of the Cinchona alkaloid related analytes. Varying the type and composition of the protic (methanol) and non-protic (acetonitrile) but polar bulk solvents in combination with organic salt additives in the mobile phase the overall retention and stereoselectivity characteristics could be triggered, leading to well performing LC and SFC systems.

Thus the retention behavior of the basic analytes on both the chiral cation-exchangers and the diastereomeric zwitterionic ion-exchangers, used as cation-exchangers, could be described by the stoichiometric displacement model related to the counter-ion effect of the mobile phase additives. In addition, it became obvious that the non-protic acetonitrile compared to methanol as bulk solvent lead to a significant increase in retention, which can be associated with an increased electrostatic interaction of the charged sites due to a smaller solvation shell of the solvated cationic and anionic species. Based on the chromatographic results of the systematically selected chiral analytes and stationary phases attempts were undertaken to interpret qualitatively the observed stereoselectivity phenomena.
\end{abstract}

(C) 2019 Elsevier B.V. All rights reserved.

\section{Introduction}

The liquid chromatographic separation and analysis of the major Cinchona alkaloids per se and in extracts of Cinchona bark have been a subject of scientific research for a long time and led to a number of publications summarized in a review by D. McCalley [1]. It is evident that HPLC in both the normal phase (NP) and reversed phase (RP) mode became the method of choice. Recently,

\footnotetext{
* Corresponding authors.

E-mail addresses: ilisz@pharm.u-szeged.hu (I. Ilisz),wolfgang.lindner@ univie.ac.at (W. Lindner).
}

a method using supercritical fluid chromatography (SFC) has also been published in context with the analysis of Cinchona bark extracts [2]. In this work non-chiral RP type and dedicated SFC type stationary phases have been investigated in terms of their selectivity spectrum to resolve the major isomers of natural Cinchona alkaloids with reasonable resolution values. In expanding the opportunities to separate not only natural Cinchona alkaloids but also some synthetic derivatives, Hoffmann presented a method using a novel strong chiral cation-exchanger (cSCX) with an unexpected selectivity [3]. The chemical structures of the major natural Cinchona alkaloids, which encompass the three pairs quinine $(\mathrm{QN})$ and quinidine (QD), dihydroquinine (DHQN) and dihydroquinidine (DHQD), 


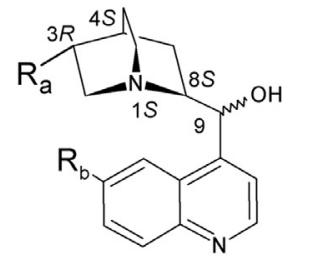

$(1 S, 3 R, 4 S, 8 S, 9 R$ or $9 S)$

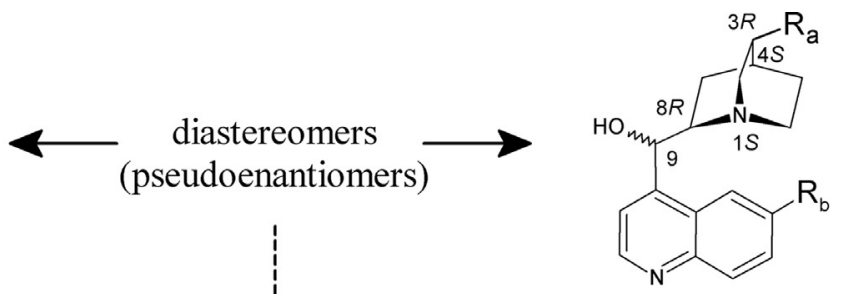

$(1 S, 3 R, 4 S, 8 R, 9 R$ or $9 S)$ abs. config.

\begin{tabular}{cc} 
Name & availability \\
\hline $\begin{array}{c}\text { Dihydro-QN } \\
\text { DH-QN }\end{array}$ & natural \\
& \\
Quinine & \\
QN & natural
\end{tabular}

Cinchonidine

CD

natural

9-epi-Quinine epi-QN synthetic
$(9 R)$

(C9)

(9R)

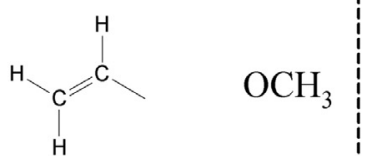

(9S)

(9S)

natural

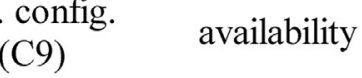

$\begin{array}{cc}\text { natural } & \begin{array}{c}\text { Dihydro-QD } \\ \text { DH-QD }\end{array}\end{array}$

${ }^{\prime} \mathrm{C}^{\prime}{ }^{\prime}$

$\mathrm{OCH}_{3}$

${ }_{\mathrm{H}}^{\mathrm{H}}=$

$(9 R)$

${ }_{\mathrm{C}}^{\mathrm{H}}=\mathrm{C}_{\mathrm{C}}^{\mathrm{C}}$

S)

)

(9S)

natural

Quinidine

QD

$(9 R)$

synthetic

9-epi-Quinidine

Cinchonine

natural

CN

epi-QD

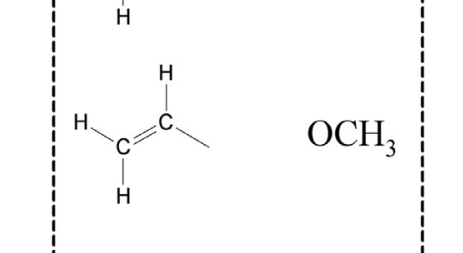

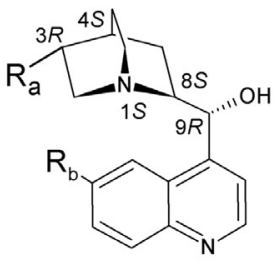

$(1 S, 3 R, 4 S, 8 S, 9 R)$

(-) Quinine (-) QN

synthetic

$(9 R)$<smiles>C=CC</smiles>

$\mathrm{OCH}_{3}$

$(9 S)$

(-) Trifluoromethylphenyl-QN synthetic

\section{(-) $\mathrm{CF}_{3} \mathrm{PQN}$}

(9R)

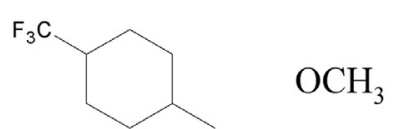

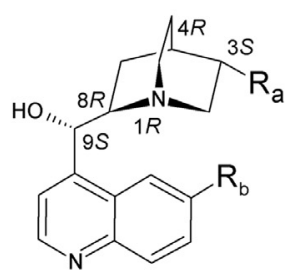

$(1 R, 3 S, 4 R, 8 R, 9 S)$

synthetic

(+) Quinine

(+) QN

synthetic

(+) Trifluoromethylphenyl-QN

(+) $\mathrm{CF}_{3} \mathrm{PQN}$

Fig. 1. Structure of natural and synthetic Cinchona alkaloids.

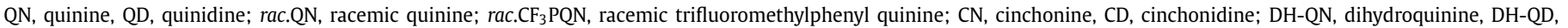
dihydroquinidine; epi-QN, 9-epi-quinine, epi-QD, 9-epi-quinidine.

cinchonidine (CD) and cinchonine $(\mathrm{CN})$ as well as the synthetic 9-epi-quinine (epi-QN) and 9-epi-quinidine (epi-QD) pair are depicted in Fig. 1. These four pairs are diastereomeric to each other, but frequently termed also pseudo-enantiomers, and are characterized by the configuration of 5 stereogenic centers. The configura- tion of the C-8 and C-9 carbon atoms switch in the case of quinine to quinidine, whereas the $1 S, 3 R$ and $4 S$ stereogenic centers of the quinuclidine ring remain constant for QN/QD, DHQN/DHQD, CD/CN, and for epi-QN/epi-QD (Fig. 1). In nature, the genuine enantiomers of $(-) \mathrm{QN}$, of $(-) \mathrm{DHQN}$ and of $(-) \mathrm{CD}$, do not exist, which 
qualified them as highly interesting targets for total synthesis concepts. These challenges could recently be mastered for $(-) \mathrm{QN}$ and $(+) \mathrm{QN}$ by Lee and Chen [4], and for racemic $( \pm)$ QN by the Maulide group [5,] via two different synthesis strategies and diastereocontrolled reaction cascades. The protocol developed by Maulide [5] allowed also the straightforward synthesis of racemic QN derivatives (see $\mathrm{CF}_{3} \mathrm{PQN}$ in Fig. 1), but not that of $\mathrm{QD}$ derivatives. In contrast, the synthesis way of Chen [4] opens up conceptually the production of $(-) \mathrm{QN}$ and $(+) \mathrm{QD}$ including the unnatural enantiomers, namely $(+) \mathrm{QN}$ and $(-) \mathrm{QD}$. The synthesis of unnatural epiQN/epi-QD was also published in detail [6]. Recently, a bio-inspired synthesis concept of $(+) C D$ and its enantiomer the natural $(-) C D$ was described as well [7].

It is a common practice to chromatographically resolve diastereoisomers on non-chiral stationary phase (e.g., on RP), because they have different physicochemical properties $[1,2,8]$. For the resolution of enantiomers, in turn, the so-called chiral stationary phases (CSPs) or other innovative separation methods are required [9-16]. Naturally, diastereomers should also be separable on CSPs. However, this may give a different spectrum of diastereoselectivity and thus the elution order of the diastereomers may vary compared to non-chiral stationary phases.

In consideration of previous investigations of separating the main natural and synthetic diastereomeric Cinchona alkaloids and some derivatives using a cSCX [3], in this study we aimed at expanding this concept substantially using (i) two pairs of enantiomeric cSCX type CSPs, and (ii) two pairs of chiral, but still diastereomeric zwitterionic Cinchona- and aminocyclohexanesulfonic acid (ACHSA)-based CSPs as depicted in Fig. 2. The focus of the present systematic investigations was on studying the stereoselectivity aspects to find correlations between molecular structure and chromatographic resolution, which includes diastereoselectivity and enantioselectivity aspects as function of the mobile phase composition and the CSPs employed. Specifically, we wanted to learn the type and composition of bulk organic solvents and of the salt additive needed for the operation of ion-exchangers. The latter strongly influences the retention characteristics of the analytes on the various "chiral columns". In addition, elution orders may be affected as a consequence of the underlying (ion pairing, ion-exchange) interaction principles of the protonated, positively charged basic analytes and the deprotonated sulfonic acid moiety of the chiral selectors. For the zwitterionic ZWIX type selectors (Fig. 2) a fixed intramolecular counter-ion effect needs also to be considered in this concept due to the positively charged quinuclidine residue (site) within the zwitterionic selector moieties. For more details on the working principles of ZWIX type selectors and CSPs for the chromatography of chiral acids, bases and ampholytes we refer to recent studies of our groups [5,17-25].

\section{Materials and methods}

\subsection{Chemicals and reagents}

Commercially available quinine $(-) \mathrm{QN}$, quinidine $(+) \mathrm{QD}$, and 10,11-dihydroquinine (-)DH-QN were purchased from Buchler (Braunschweig, Germany), while 10,11-dihydroquinidine (+)DH-QD, cinchonine $(\mathrm{CN})$, and cinchonidine $(\mathrm{CD})$ were from Sigma-Aldrich (Vienna, Austria). C9-epiquinine (-)epi-QN and C9-epiquinidine (+)epi-QD were synthesized according to the literature [7] (Fig. 1). Racemic quinine, 1:1 mixture of $(-) \mathrm{QN}$ and $(+) \mathrm{QN}$ as well as of racemic trifluoromethylphenyl quninine $\left(\right.$ rac. $\left.\mathrm{CF}_{3} \mathrm{PQN}\right)$ were a generous gift of N. Maulide and was synthesized according to [5].

Methanol $(\mathrm{MeOH})$ and acetonitrile $(\mathrm{MeCN})$ of HPLC grade were purchased from VWR International (Arlington Heights, IL, USA). The base additive diethylamine (DEA), the acid additive formic acid (FA) and ammonium acetate $\left(\mathrm{NH}_{4} \mathrm{OAc}\right)$, all analytical reagent grades, were from VWR. Liquid $\mathrm{CO}_{2}$ was from Messer (Budapest, Hungary).

\subsection{Apparatus and chromatography}

Liquid chromatography was performed on two chromatographic systems. Waters Breeze apparatus consisted of a 1525 binary pump, a 487 dual-channel absorbance detector, a 717 plus autosampler, a column thermostat and, for data acquisition, the Empower 2 data manager software (Waters Corporation, Milford, MA, USA). 1100 Agilent system contained a solvent degasser, a pump, an autosampler, a column thermostat, a multi-wavelength UVVis detector, and a Chemstation chromatographic data software (Agilent Technologies, Waldbronn, Germany). Experiments in polar ionic mode (PIM) were carried out in isocratic mode at a flow rate of $0.6 \mathrm{ml} \mathrm{min}-1$ and column temperature $25^{\circ} \mathrm{C}$.

For subcritical liquid chromatography (SFC) the Waters Acquity Ultra Performance Convergence Chromatography ${ }^{\mathrm{TM}}$ (UPC $^{2}$, Waters Corporation) system was applied with a binary solvent pump, an autosampler with injection system, a backpressure regulator, a column oven, and a PDA detector. For system control and data acquisition the Empower 2 software was used. SFC was performed in isocratic mode at a flow rate of $2.0 \mathrm{ml} \mathrm{min}^{-1}$ and column temperature $40{ }^{\circ} \mathrm{C}$. The outlet pressure was maintained at $150 \mathrm{bar}$. The mobile phase consisted of $\mathrm{CO}_{2}$ and $\mathrm{MeOH}$ in different ratios (v/v) and contained different additives (acids, bases, salts).

Stock solutions of different Cinchona alkaloids were prepared in $1.0 \mathrm{mg} \mathrm{ml}^{-1}$ concentration and further diluted when necessary. Dead-time of columns $\left(t_{0}\right)$ in LC mode was determined by injecting methanolic solution of acetone and in SFC mode at a first negative signal by injecting $\mathrm{MeOH}$ (see footnotes to Tables). In both chromatographic techniques analytes were detected by UV absorption at $215-230 \mathrm{~nm}$.

The synthesis of all investigated chiral stationary phases (and the chiral columns thereof) investigated in this study depicted in Fig. 2, has already been described previously. Specifically, the development of DCL- $(R, R)$ - and DCL-(S,S)- as well as DML- $(R, R)-$ and DML- $(S, S)(150 \times 4.0 \mathrm{~mm}$ I.D., $5-\mu \mathrm{m}$ particle size $)$-CSPs is found in the paper by Wolrab et al. [26]; the development of ZWIX(+) and ZWIX(-) columns was described in the paper by Hoffmann et al. [17] and Zhang [27]; and the development of the ZWIX(-A) and ZWIX $(+A)(150 \times 3.0 \mathrm{~mm}$ I.D., 3- $\mu \mathrm{m}$ particle size $)$ columns was disclosed in the paper by Grecsó et al. [14]. The commercially available Chiralpak ZWIX $(+)$ and ZWIX $(-)$ columns $(150 \times 3.0 \mathrm{~mm}$ I.D., $3-\mu \mathrm{m}$ particle size) were provided by Chiral Technologies Europe (Illkirch, France).

\section{Results and discussion}

\subsection{Selection of the CSPS}

The common structured core of all eight investigated CSPs employed as chiral strong cation-exchangers as depicted in Fig. 2 is characterized by the chiral trans-aminocyclohexanesulfonic acid moiety either in the $(R, R)$ or in the $(S, S)$ configuration. These enantiomeric units are linked via an amide and the functionally related carbamoyl group, respectively, to non-chiral or chiral subunits, which provide additional interaction sites of the entire selector (SO) motifs with the Cinchona-type analytes, the selectands (SAs). This concept led for the genuine cation-exchanger to two pairs of enantiomeric CSPs and columns (Fig. 2). Besides the stereochemical differentiation, they differ also in the $\pi$-electron density of the aryl group.

The second group of four chiral ion-exchangers belong formally to the so-called zwitterionic type CSPs due to the formal fusion of molecules containing the basic quinuclidine residue 


\section{Strong Cation Exchanger Type CSPs}

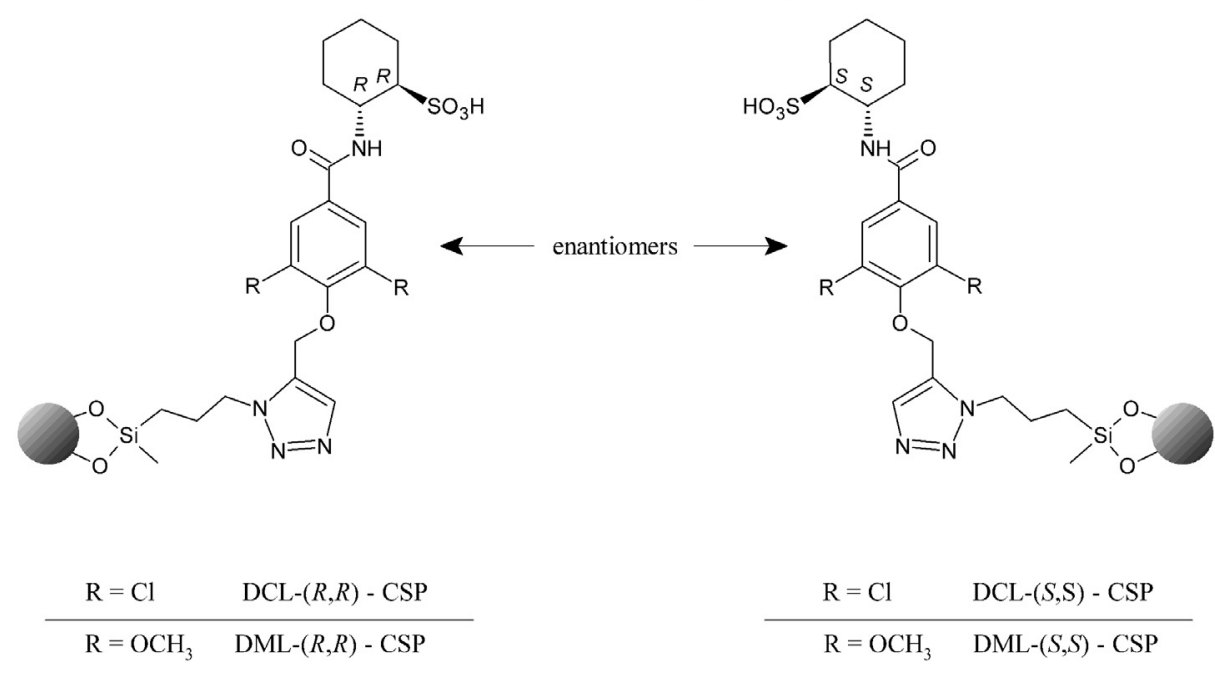

\section{Zwitterionic Type CSPs}

QN subunit

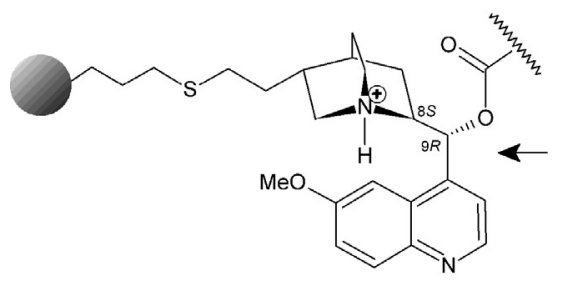

QD subunit

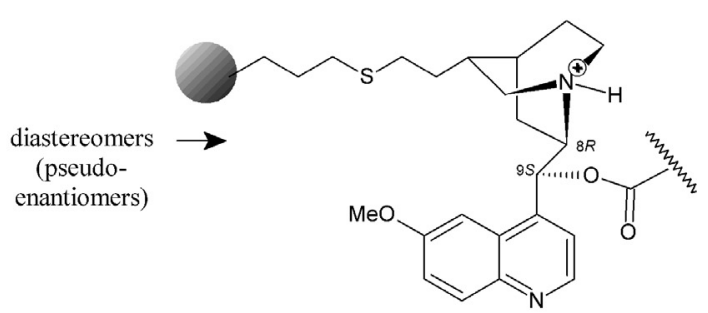

$(R, R) /(S, S)$-ACHSA subunits
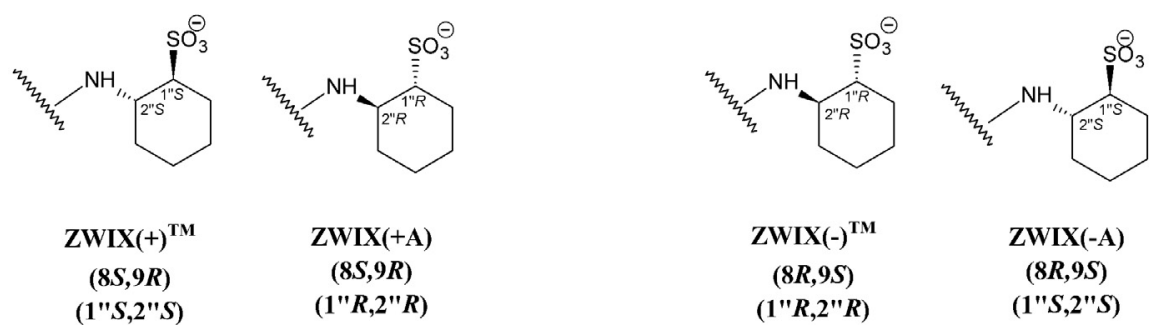

Fig. 2. Structure of strong cation-exchanger and zwitterionic Cinchona alkaloid-based chiral selectors.

with the aminocyclohexanesulfonic acid residue. In the present case this fused basic molecule scaffold relates to the diastereomeric Cinchona alkaloids, namely to quinine and quinidine, which often behave as pseudo-enantiomers of each other. This concept led to the four (two pairs) zwitterionic CSPs (and the related ion-exchanger type columns), which may behave pseudoenantiomerically to each other, namely the $\operatorname{ZWIX}(+) / Z W I X(-)$ and ZWIX $(+\mathrm{A}) / \mathrm{ZWIX}(-\mathrm{A})$ pairs.

The aims of our investigations, were (a) the elucidation of the retention characteristics of the eight chiral ion-exchangers (four genuine cation-exchangers and four zwitterionic ion-exchangers employed as cation-exchanger) as a function of mobile phase compositions, and (b) evaluation of the enantio- and diastereoselectivity of these structurally and functionally related CSPs for the carefully selected basic analytes of the Cinchona type compounds (Fig. 1). The comparisons were carried out in a systematic fashion whereby the focus of the discussion was placed on the stereos- electivity properties of the eight CSPs. The discussion is based on the assigned elution orders of all the pseudo-enantiomeric (still diastereomeric) quinine/quinidine type analytes and the truly enantiomeric racemic quinine analogs.

\subsection{Chromatographic evaluation of the CSPs in LC and SFC}

\subsection{1. cSCX columns in LC modality}

As known from previous studies [19], these chiral ion-exchanger columns can be conveniently operated in a non-aqueous mobile phase using $\mathrm{MeOH}$ as bulk solvent and an organic salt as counterion source (polar ionic mode, PIM). Based on initial experiments (data not shown) we selected conditions, which led to reasonable retention times of the basic analytes. Naturally, the retention times could have been further optimized via the counter-ion concentration in the mobile phase, but this was beyond the aim of the present study, which deals primarily with stereoselectivity 
Table 1

Chromatographic data, $k_{1}, k_{2}, \alpha, R_{S}$, plate numbers and elution sequence of Cinchona alkaloid analogs on strong cation-exchanger chiral stationary phases.

\begin{tabular}{|c|c|c|c|c|c|c|c|}
\hline Compound & $k_{1}$ & $k_{2}$ & $\alpha$ & $R_{S}$ & $N_{1}$ & $\mathrm{~N}_{2}$ & Elution order \\
\hline \multicolumn{8}{|c|}{ DCL- $(S, S)$} \\
\hline QN/QD & 6.74 & 9.17 & 1.36 & 5.16 & 5762 & 6297 & $(-) \mathrm{QN}<(+) \mathrm{QD}$ \\
\hline rac.QN & 6.73 & 7.09 & 1.05 & 0.73 & 4790 & 4600 & $(-) \mathrm{QN}<(+) \mathrm{QN}$ \\
\hline $\operatorname{rac} . \mathrm{CF}_{3} \mathrm{PQN}$ & 2.56 & 2.56 & 1.00 & 0.00 & 2722 & - & - \\
\hline DH-QN/DH-QD & 10.35 & 13.87 & 1.34 & 5.44 & 6400 & 6505 & $(-) \mathrm{DH}-\mathrm{QN}<(+) \mathrm{DH}-\mathrm{QD}$ \\
\hline epi-QN/epi-QD & 9.07 & 9.07 & 1.00 & 0.00 & 1660 & - & - \\
\hline $\mathrm{CD} / \mathrm{CN}$ & 5.28 & 7.08 & 1.34 & 4.17 & 6305 & 7055 & $\mathrm{CD}<\mathrm{CN}$ \\
\hline \multicolumn{8}{|c|}{$\mathrm{DCL}-(R, R)$} \\
\hline QN/QD & 6.79 & 8.35 & 1.23 & 4.27 & 8521 & 8615 & $(-) \mathrm{QN}<(+) \mathrm{QD}$ \\
\hline rac.QN & 6.38 & 6.76 & 1.06 & 1.17 & 8163 & 8106 & $(+) \mathrm{QN}<(-) \mathrm{QN}$ \\
\hline rac. $\mathrm{CF}_{3} \mathrm{PQN}$ & 2.31 & 2.40 & 1.04 & 0.20 & 915 & 1152 & n.d. \\
\hline DH-QN/DH-QD & 10.31 & 12.37 & 1.20 & 3.96 & 8955 & 9345 & $(-) \mathrm{DH}-\mathrm{QN}<(+) \mathrm{DH}-\mathrm{QD}$ \\
\hline epi-QN//epi-QD & 8.06 & 8.79 & 1.09 & 1.68 & 7789 & 7117 & $(-)$ epi-QN $<(+)$ epi-QD \\
\hline $\mathrm{CD} / \mathrm{CN}$ & 5.77 & 5.77 & 1.00 & 0.00 & 8163 & - & - \\
\hline \multicolumn{8}{|c|}{ DML- $(S, S)$} \\
\hline QN/QD & 1.76 & 2.45 & 1.39 & 4.22 & 4925 & 5851 & $(-) \mathrm{QN}<(+) \mathrm{QD}$ \\
\hline rac.QN & 1.76 & 1.99 & 1.13 & 1.42 & 5117 & 5043 & $(-) \mathrm{QN}<(+) \mathrm{QN}$ \\
\hline rac. $\mathrm{CF}_{3} \mathrm{PQN}$ & 0.84 & 0.92 & 1.09 & 0.75 & 3483 & 3300 & n.d. \\
\hline DH-QN/DH-QD & 2.65 & 3.63 & 1.37 & 4.39 & 4620 & 5420 & $(-) \mathrm{DH}-\mathrm{QN}<(+) \mathrm{DH}-\mathrm{QD}$ \\
\hline epi-QN//epi-QD & 2.35 & 2.35 & 1.00 & 0.00 & 2850 & - & - \\
\hline $\mathrm{CD} / \mathrm{CN}$ & 1.57 & 2.04 & 1.30 & 2.13 & 2972 & 4264 & $\mathrm{CD}<\mathrm{CN}$ \\
\hline \multicolumn{8}{|c|}{$\mathrm{DML}-(R, R)$} \\
\hline QN/QD & 4.46 & 5.53 & 1.24 & 3.94 & 7752 & 7372 & $(-) \mathrm{QN}<(+) \mathrm{QD}$ \\
\hline rac.QN & 4.07 & 4.48 & 1.10 & 1.72 & 7612 & 7787 & $(+) \mathrm{QN}<(-) \mathrm{QN}$ \\
\hline rac. $\mathrm{CF}_{3} \mathrm{PQN}$ & 1.54 & 1.68 & 1.09 & 0.85 & 6377 & 6227 & n.d. \\
\hline DH-QN/DH-QD & 6.70 & 7.97 & 1.19 & 3.51 & 8196 & 8267 & $(-) \mathrm{DH}-\mathrm{QN}<(+) \mathrm{DH}-\mathrm{QD}$ \\
\hline epi-QN//epi-QD & 5.74 & 6.26 & 1.09 & 1.32 & 1337 & 1498 & $(-) e p i-\mathrm{QN}<(+)$ epi-QD \\
\hline $\mathrm{CD} / \mathrm{CN}$ & 3.65 & 3.83 & 1.05 & 0.65 & 4807 & 2859 & $\mathrm{CD}<\mathrm{CN}$ \\
\hline
\end{tabular}

Chromatographic conditios: columns, DCL- $(S, S)$, DCL- $(R, R)$, DML-(S,S), DML- $(R, R)$; mobile phase, MeOH

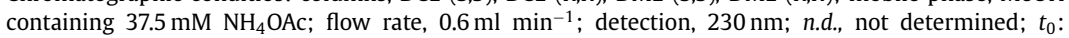
DCL-(S,S), 2.87 min; DCL-(R,R), 2.79 min; DML-(S,S), 2.99 min; DML- $(R, R), 2.97 \mathrm{~min}$.

aspects in connection with the resolution of the stereoisomeric Cinchona alkaloid analogues (Fig. 1), including the unique racemic $( \pm)$-quinine $[( \pm)-Q N]$ and the racemic trifluorinated $( \pm)$-quinine analogue $\left[( \pm)-\mathrm{CF}_{3} \mathrm{PQN}\right]$. As evidenced by the summarized chromatographic data in Tables 1 and 2, several unexpected characteristic features can be extracted.

a) The retention times of all six pairs of stereoisomers of the natural and synthetic Cinchona alkaloid analogues are significantly higher on the DCL-type cSCX columns compared to the DMLtype cSCX columns (Table 1). Whether or not the different $\pi$ electron densities and $\mathrm{H}$-bond formation abilities of the DML and DCL selector moieties contribute to the different retention characteristics cannot be answered here (Fig. 2). In accordance with previous observations [3], a marked increase in the retention times of the DHQN/DHQD pair compared to the QN/QD pair has also been noted. It is rather surprising as the very slightly increased hydrophobicity of the DHQN/DHQD analytes has such an effect for an ion-exchanger type system. To be more specific, the ion-exchanger (see Fig. 2) should be classified as a so-called mixed type stationary phase by combining ionic and hydrophobic interactions sites. For the present cases the enhanced retention seems to be originated from a cooperative effect of the slightly increased hydrophobicity and ionization of the dihydro compounds.

b) The novel racemic compounds $( \pm)-\mathrm{QN}$ and $( \pm)-\mathrm{CF}_{3} \mathrm{PQN}$ can essentially be resolved on all four cSCX columns with the exception of $\mathrm{CF}_{3} \mathrm{PQN}$ on the $\mathrm{DCL}(S, S)$-column. The enantiomers of racemic $( \pm) \mathrm{QN}$ are baseline resolved on the enantiomeric DML$(S, S)$ and on the DML- $(R, R)$ columns with the expected reversal of elution order, following the rule of reciprocity. In concrete, for the $(S, S)$-configurated SO the elution order is $(-) \mathrm{QN}$ before
$(+) \mathrm{QN}$, whereas for the $(R, R)$-configurated SO the elution order is reversed, thus $(+) \mathrm{QN}$ elutes before $(-) \mathrm{QN}$.

c) It is somewhat unexpected to find the same elution order of the diastereomeric pairs of $Q N / Q D, D H Q N / D H Q D$, and of $C D / C N$ on all four enantiomeric cSCX columns (except CD/CN on DCL$(R, R)$ column) being $\mathrm{QN}<\mathrm{QD}, \mathrm{DHQN}<\mathrm{DHQD}$, and $\mathrm{CD}<\mathrm{CN}$. An explanation for this behavior obviously has to deal with the constant configuration of the three chiral atoms (1S), (3R) and $(4 S)$ of the quinuclidine residue being part of all the diastereomeric analytes whereas the configuration of the C-8 and C-9 atoms switch from $(8 S, 9 R)$ to $(8 R, 9 S)$ for QD/DHQD and $\mathrm{CN}$. The configuration of the protonated and thus positively charged nitrogen $(1 S)$ remains for all the diastereomeric analytes constant, which indicates that the reversed configuration of the C-8 and C-9 atoms are the only variables. The electrostatically driven ion pairing of the negatively charged sites of the enantiomeric $(R, R)$ - and $(S, S)$-selectors and of the constantly configurated and positively charged $(1 S)$ site of the diastereomeric SAs becomes dominant for the overall retention and for the elution order characteristics. The contributions of all the other more or less stereochemically driven SO-SA interaction increments remain uninterpretable at this point. It is a qualitative statement on the chromatographic observations, however, for a more detailed elucidation of the entire intermolecular SO-SA interactions more sophisticated techniques as e.g. dedicated NMR experiments of the diastereomeric SO-SA associates would be needed. However, this is beyond the aim of this study. Regarding the elution order, the stereochemically equal $\mathrm{CD} / \mathrm{CN}$ pair behaves similarly to the $\mathrm{QN} / \mathrm{QD}$ pair, only the overall retention decreases as a consequence of the missing methoxy group of the quinoline ring which leads to decreased hydrophobicity. 
Table 2

Chromatographic data, $k_{1}, k_{2}, \alpha, R_{S}$, plate numbers and elution sequence of Cinchona alkaloid analogs on zwitterionic chiral stationary phases in PI mode.

\begin{tabular}{|c|c|c|c|c|c|c|c|}
\hline Compound & $k_{1}$ & $k_{2}$ & $\alpha$ & $R_{S}$ & $N_{1}$ & $\mathrm{~N}_{2}$ & Elution order \\
\hline \multicolumn{8}{|c|}{ ZWIX(-) } \\
\hline QN/QD & 0.76 & 1.03 & 1.36 & 2.52 & 4333 & 2931 & $(-) \mathrm{QN}<(+) \mathrm{QD}$ \\
\hline rac.QN & 0.74 & 0.92 & 1.25 & 1.17 & 4270 & 3694 & $(-) \mathrm{QN}<(+) \mathrm{QN}$ \\
\hline rac. $\mathrm{CF}_{3} \mathrm{PQN}$ & 0.52 & 0.60 & 1.16 & 0.67 & 4617 & 3233 & \\
\hline DH-QN/DH-QD & 0.74 & 1.02 & 1.38 & 2.70 & 4343 & 3397 & $(-) \mathrm{DH}-\mathrm{QN}<(+) \mathrm{DH}-\mathrm{QD}$ \\
\hline epi-QN/epi-QD & 0.62 & 0.83 & 1.34 & 1.87 & 1844 & 2588 & $(-) e p i-\mathrm{QN}<(+) e p i-\mathrm{QD}$ \\
\hline $\mathrm{CD} / \mathrm{CN}$ & 0.84 & 0.84 & 1.00 & 0.00 & 3218 & - & - \\
\hline $\mathrm{CD} / \mathrm{CN}^{*}$ & 3.36 & 3.86 & 1.15 & 3.36 & 14726 & 10080 & $\mathrm{CN}<\mathrm{CD}$ \\
\hline \multicolumn{8}{|c|}{$\mathrm{ZWIX}(-\mathrm{A})$} \\
\hline QN/QD & 1.37 & 1.42 & 1.04 & 0.54 & 3101 & 2562 & $(+) \mathrm{QD}<(-) \mathrm{QN}$ \\
\hline rac.QN & 1.42 & 1.60 & 1.12 & 1.44 & 6694 & 7132 & $(-) \mathrm{QN}<(+) \mathrm{QN}$ \\
\hline rac. $\mathrm{CF}_{3} \mathrm{PQN}$ & 1.35 & 1.52 & 1.12 & 1.07 & 6757 & 6520 & n.d. \\
\hline DH-QN/DH-QD & 1.39 & 1.47 & 1.06 & 0.68 & 2106 & 3091 & $(+) \mathrm{DH}-\mathrm{QD}<(-) \mathrm{DH}-\mathrm{QN}$ \\
\hline epi-QN/epi-QD & 0.96 & 1.02 & 1.06 & 0.61 & 4036 & 3150 & $(+) e p i-Q D<(-) e p i-Q N$ \\
\hline $\mathrm{CD} / \mathrm{CN}$ & 1.28 & 1.85 & 1.44 & 3.79 & 3237 & 6573 & $\mathrm{CN}<\mathrm{CD}$ \\
\hline \multicolumn{8}{|c|}{ ZWIX(+) } \\
\hline QN/QD & 1.21 & 1.45 & 1.20 & 2.32 & 5285 & 5795 & $(+) \mathrm{QD}<(-) \mathrm{QN}$ \\
\hline rac.QN & 1.12 & 1.43 & 1.28 & 2.36 & 6995 & 6396 & $(+) \mathrm{QN}<(-) \mathrm{QN}$ \\
\hline rac. $\mathrm{CF}_{3} \mathrm{PQN}$ & 0.80 & 0.98 & 1.23 & 1.65 & 6490 & 5985 & n.d. \\
\hline DH-QN/DH-QD & 1.20 & 1.44 & 1.20 & 2.46 & 6843 & 6239 & $(+) \mathrm{DH}-\mathrm{QD}<(-) \mathrm{DH}-\mathrm{QN}$ \\
\hline epi-QN/epi-QD & 1.14 & 1.14 & 1.00 & 0.00 & 2216 & - & - \\
\hline epi-QN/epi-QD* & 4.54 & 4.54 & 1.00 & 0.00 & 7630 & - & - \\
\hline $\mathrm{CD} / \mathrm{CN}$ & 1.37 & 1.47 & 1.07 & 0.87 & 6076 & 6899 & $\mathrm{CD}<\mathrm{CN}$ \\
\hline \multicolumn{8}{|c|}{$\mathrm{ZWIX}(+\mathrm{A})$} \\
\hline QN/QD & 1.60 & 2.03 & 1.27 & 3.24 & 7419 & 7191 & $(+) \mathrm{QD}<(-) \mathrm{QN}$ \\
\hline rac.QN & 1.71 & 2.02 & 1.18 & 2.44 & 8071 & 7877 & $(+) \mathrm{QN}<(-) \mathrm{QN}$ \\
\hline rac. $\mathrm{CF}_{3} \mathrm{PQN}$ & 1.50 & 1.84 & 1.22 & 2.72 & 7597 & 7331 & n.d. \\
\hline DH-QN/DH-QD & 1.62 & 2.09 & 1.29 & 3.65 & 8145 & 7502 & $(+) \mathrm{DH}-\mathrm{QD}<(-) \mathrm{DH}-\mathrm{QN}$ \\
\hline epi-QN/epi-QD & 1.18 & 1.48 & 1.26 & 2.80 & 7332 & 6792 & $(-) e p i-Q N<(+) e p i-Q D$ \\
\hline $\mathrm{CD} / \mathrm{CN}$ & 1.83 & 2.05 & 1.12 & 1.55 & 6326 & 7073 & $\mathrm{CN}<\mathrm{CD}$ \\
\hline
\end{tabular}

Chromatographic conditions: column, ZWIX(-), ZWIX (+), ZWIX(-A) and ZWIX (+A); mobile phase, $\mathrm{MeOH} / \mathrm{MeCN}(50 / 50 \mathrm{v} / \mathrm{v})$ containing $25 \mathrm{mM}$ DEA and $50 \mathrm{mM} \mathrm{FA},{ }^{*} \mathrm{MeOH} / \mathrm{MeCN}(10 / 90 \mathrm{v} / \mathrm{v})$ containing $25 \mathrm{mM}$ DEA and $50 \mathrm{mM} \mathrm{FA}$; flow rate, $0.6 \mathrm{ml} \mathrm{min}{ }^{-1}$; detection, $215-230 \mathrm{~nm}$; temperature, $25^{\circ} \mathrm{C}$; n.d., not determined; $t_{0}: \operatorname{ZWIX}(-)^{\mathrm{TM}} 1,51 \mathrm{~min}, \mathrm{ZWIX}(-\mathrm{A}) 1.53 \mathrm{~min}, \mathrm{ZWIX}(+)^{\mathrm{TM}} 1.55 \mathrm{~min}$, ZWIX $(+\mathrm{A})$ $1.56 \mathrm{~min}$.

d) The behavior of the diastereomeric 9-epi-QN/9-epi-QD pair compared to that of the QN/QD pair is again unexpected. Retention times increase in all cases, which indicates that most probably the electrostatic interactions of the charged quinuclidine and the sulfonic acid sites become stronger. It has to be attributed to the specific stereochemistry of the C-9 atom in relation to the chiral $\mathrm{C}-8$ atom and thus to the different sterical direction of $\mathrm{OH}$-group (compared to $\mathrm{QN}$ and $\mathrm{QD}$ ), and as a result the overall conformation of the analytes is significantly altered. As a consequence, it can be hypothesized that the positively charged quinuclidine site gets better accessible by the negatively charged sulfonic acid sites of the SOs. Both the DCL$(R, R)$ and the DML- $(R, R)$ SOs (columns) recognize stereoselectively the diastereomers of 9-epi-QN and 9-epi-QD, whereas the enantiomeric DCL- $(S, S)$ and DML- $(S, S)$ SOs don't provide diastereoselectivity for these analytes.

In the next set of studies, we extended the structural modification of the CSCX SOs with integrating positively charged sites into the selector design in favor of chiral QN and QD residues thus leading to ampholytic (zwitterionic) CSPs, which will be discussed in the forthcoming section.

\subsubsection{Chiral ZWIX columns in LC modality}

The intrinsic characteristics of (chiral) zwitterionic stationary phases is their flexibility to be used as (chiral) cation-exchanger for the resolution of chiral bases, as (chiral) anion-exchanger for the separation of chiral acids and as (chiral) zwitterionic ion-exchanger for the resolution of the enantiomers of ampholytic analytes. There are plenty of examples for these three application modes, for the resolution of chiral acids [17-19], chiral bases [20] and chiral ampholytes, e.g., free amino acids and small peptides [21-25].

Ion-exchangers need inorganic or organic counter-ions in the mobile phase to adjust the retention. These are protonated bases for cation-exchangers, while deprotonated acids for anionexchangers. However, in principle, free bases and acids could also be used assuming proton transfer events. For the investigated zwitterionic ion-exchangers an intramolecular ion pairing effect can be postulated due to the positively charged quinuclidine residue (site) within the zwitterionic QN/QD type selector moieties. This will essentially influence the amount of counter-ions needed in the mobile phase to adjust retention times. However, for the present study, only organic acids and bases are employed as counter-ions. They work for both sites of the ampholytic selector characterized by the acidic and basic functional groups (Fig. 2).

In continuation of the experiments with the cSCX columns, the main goal of this part of the project was to elucidate the retention and molecular recognition capacities of the four rationally designed ZWIX phases and columns (Fig. 2) in a comparative way for the six natural and synthetic Cinchona alkaloid analogues. Table 2 lists a representative set of chromatographic results, which will be interpreted in detail in the following.

The two pairs of $\operatorname{ZWIX(}(-)$ and $\operatorname{ZWIX}(+)$ as well as $\operatorname{ZWIX}(-\mathrm{A})$ and $\mathrm{ZWIX}(+\mathrm{A})$ SOs are diastereomers, but could also be considered as pseudo-enantiomeric phases, as has frequently been proven for the resolution of the enantiomers of free amino acids [2,20]. In such cases a reversal of elution order will be obvious. Consequently, this concept was similarly valid for the resolution of 
racemic ( \pm )-quinine as found for the enantiomeric cSCX type CSPs and columns, but in a slightly different manner.

Inspecting the set of data in Table 2 , it becomes obvious that the retention times are significantly lower. This might be attributed on one hand to the increased counter-ion concentration, and on the other hand to a repulsion effect caused by the anion-exchanger site of the zwitterionic phases. The type of bulk solvent composition has also a strong effect (see data marked with asterisks). Decreasing the amount of the protic $\mathrm{MeOH}$ in a mixture with $\mathrm{MeCN}$ leads to a strong increase of retention time, which can be attributed to a decreased thickness of the solvent sphere (solvation shell) around the ionized sites of the SO and of the selectand (SA, analyte) moiety. This is a known phenomenon which can directly be translated to the strength of the effective electrostatic interaction of the positively and negatively charged sites in their solvated status. The non-protic MeCN solvates less strongly than a protic solvent thus the radius of solvated ion changes. The significance of this behavior is visualized in Fig. 3. Keeping the organic salt and acid concentration constant in pure polar, but non-protic $\mathrm{MeCN}$, the retention is roughly ten times higher than that in pure polar, but protic $\mathrm{MeOH}$ as bulk solvent, following a non-linear curve. As expected, the composition of the bulk solvent has an effect on the overall stereoselectivity and finally also on the efficiency of the chiral columns. Selected data are depicted in Fig. 3 and summarized in Table S1 for the ZWIX(+) and ZWIX(-) columns and for a set of four Cinchona alkaloid type analytes (Issues related to molecular recognition and elution order of the stereoisomers will be discussed later.).

\subsubsection{Effect of the counter-ion concentration in the mobile phase}

For basic analytes, it is generally accepted that an ion pairing process occurs with the sulfonic acid site of the chiral selector of the cSCX columns. Protonated bases as counter-ions in the mobile phase are needed to elute the analyte, whereby their concentration is directly correlated to the retention factor and can be evaluated by a stoichiometric displacement model [28].

Accordingly, we investigated the validity of the model for the zwitterionic ZWIX columns as well by varying the amount of the base in the mobile phase. Under the given conditions we see a clear linear relationship between the log values of the retention factors and the log of the base (actually, the protonated base) concentration in the mobile phase, as shown in Fig. 4. (The corresponding chromatographic data are summarized in Table S2). This information represents the ratios of effective charges of the analytes and of the counter-ion in the bulk phase. The linear correlation (characterized with correlation coefficients higher than 0.979 for all the investigated columns and analytes) justifies the validity of the stoichiometric displacement model. Carefully inspecting the values for the slopes (Fig. 4), it becomes obvious that they are not entirely equal, but relatively similar with some exceptions. For pure $\mathrm{MeOH}$ as bulk solvent the slopes of epi-QN/epi-QD differ significantly, compared to the other three sets of analytes. This trend of deviation of epi-QN/epi-QD becomes even more pronounced for the $1: 1$ mixture of $\mathrm{MeOH}$ and $\mathrm{MeCN}$ bulk solvents.

The experimental findings corroborate also a significant effect of the solvation shell of the ionized sites. At this point, it should be emphasized that the solvent compositions of the solvation shell must not necessarily be the same as that of the bulk solvent mixture of the mobile phase. Therefore, interpretation of the experimental findings is difficult and needs further studies, which are currently ongoing.

\subsubsection{Chiral ZWIX columns in SFC modality}

As it has been investigated earlier, chiral ion-exchangers can in principle be operated in hydro-organic, in polar organic, and in
SFC modes using liquid $\mathrm{CO}_{2}$ with adapted bulk solvent compositions, but always containing appropriate amounts of organic salts in the mobile phase acting as counter-ions [29]. Based on these information, the two $\mathrm{ZWIX}(+)$ and $\mathrm{ZWIX}(-)$ columns have been investigated in SFC modality using liquid $\mathrm{CO}_{2}$ mixed with various amounts of $\mathrm{MeOH}$. From the inspection of the data summarized in Table 3, it is evident that, as expected, the retention factors of the six pairs of stereoisomeric Cinchona alkaloid analogues are strongly dependent on the amount of $\mathrm{MeOH}$ in the liquid $\mathrm{CO}_{2} / \mathrm{MeOH}$ mixtures. On the basis of these preliminary findings, the comparison of the retention factors of the investigated analytes (visualized in Fig. 3 and listed in Table 3) gives a surprising result. Namely, liquid $\mathrm{CO}_{2}$ at 150 bar and at $40^{\circ} \mathrm{C}$, compared to $\mathrm{MeCN}$ as a bulk solvent applied in a mixture with $10 \mathrm{v} \% \mathrm{MeOH}$ in LC modality, appears to be less "polar" than the non-protic, but polar MeCN. (For the compared ion-exchange systems the counter-ion concentrations were identical).

This rather preliminary statement and observation are in conjunction with ion-exchange chromatography operated under supercritical and subcritical conditions, which is a subject of ongoing investigations [30]. Liquid $\mathrm{CO}_{2}$ behaves as a somewhat polar solvent with hydrogen bonding properties, which makes it fully mixable with the polar, protic $\mathrm{MeOH}$ at pressurized conditions. With higher $\mathrm{MeOH}$ content in the mobile phase, the stereoselectivity becomes slightly higher for the resolution of QN/QD. A similar trend was observed under LC conditions in the PI mode (with the exception of ZWIX(+)). The listed selectivity values were measured at $40^{\circ} \mathrm{C}$, whereas selectivities for the LC modality were measured at $25^{\circ} \mathrm{C}$, which may bias a direct comparison of the stereoselectivity data to some extent.

\subsubsection{Stereoselectivity and elution order}

In comparison to the cSCX columns, it became evident that the enantiomers of racemic quinine $( \pm) \mathrm{QN}$ and $( \pm) \mathrm{CF}_{3} \mathrm{PQN}$ can be well resolved on ZWIX columns in almost all cases, but with greater $\alpha$-values (see Tables 1 and 2). The elution order of the $\mathrm{QN}$ enantiomers on $\operatorname{ZWIX}(-)$ and $\operatorname{ZWIX}(-\mathrm{A})$ is $(-) \mathrm{QN}<(+) \mathrm{QN}[(-) \mathrm{QN}$ is the natural alkaloid]. However, it is reversed on $\operatorname{ZWIX}(+)$ and $\mathrm{ZWIX}(+\mathrm{A})$ and becomes $(+) \mathrm{QN}<(-) \mathrm{QN}$. Therefore, these two sets of chiral columns behave pseudo-enantiomerically to each other. For the combination of QD with the $(S, S)$-ACHSA, which refers to the ZWIX(-A) selector, one observes the same elution order as for genuine $(S, S)$-ACHSA-based cSCX. The same trend, but a reversed elution order have been observed for the $(R, R)$-ACHSA related chiral columns, namely for $\operatorname{ZWIX}(+\mathrm{A})$ and the DCL- $(R, R)$ and DML$(R, R)$ columns.

For a better visualization of the enantioselectivity and diastereoselectivity of the eight chiral selectors for the five pairs of Cinchona alkaloid stereoisomers, related chromatographic information has been summarized in Table 4. All data are based on comparable LC mode measurements, and in two cases, for the $\mathrm{ZWIX}(+)$ and the ZWIX(-) columns, the SFC modality has also been investigated. For the separation of enantiomers, consistencies have been noticed many times, but for the elution order (and resolution) of the diastereomers, including the epimers, several inconsistencies have also been observed. It is obvious that the QN and QD subunit in combination with the $(R, R)$ - and $(S, S)$-ACHSA core, dedicated for a chiral cation-exchanger type CSP, may have a marked influence on the overall molecular recognition, leading to unpredicted elution sequence of the diastereomeric analytes. In principle, this is not surprising for the presented examples, since it gives evidence for the combinatorial effect of "chiral information" stemming from two different chiral subunits fused together via a carbamoyl linker. This observation indicates that the stereoselectivity driven by the absolute configuration, e.g., of the (S,S)-ACHSA unit, is not disturbed by its fusion with the QD subunit. In contrast, its 
ZWIX(+) $)^{\mathrm{TM}}$
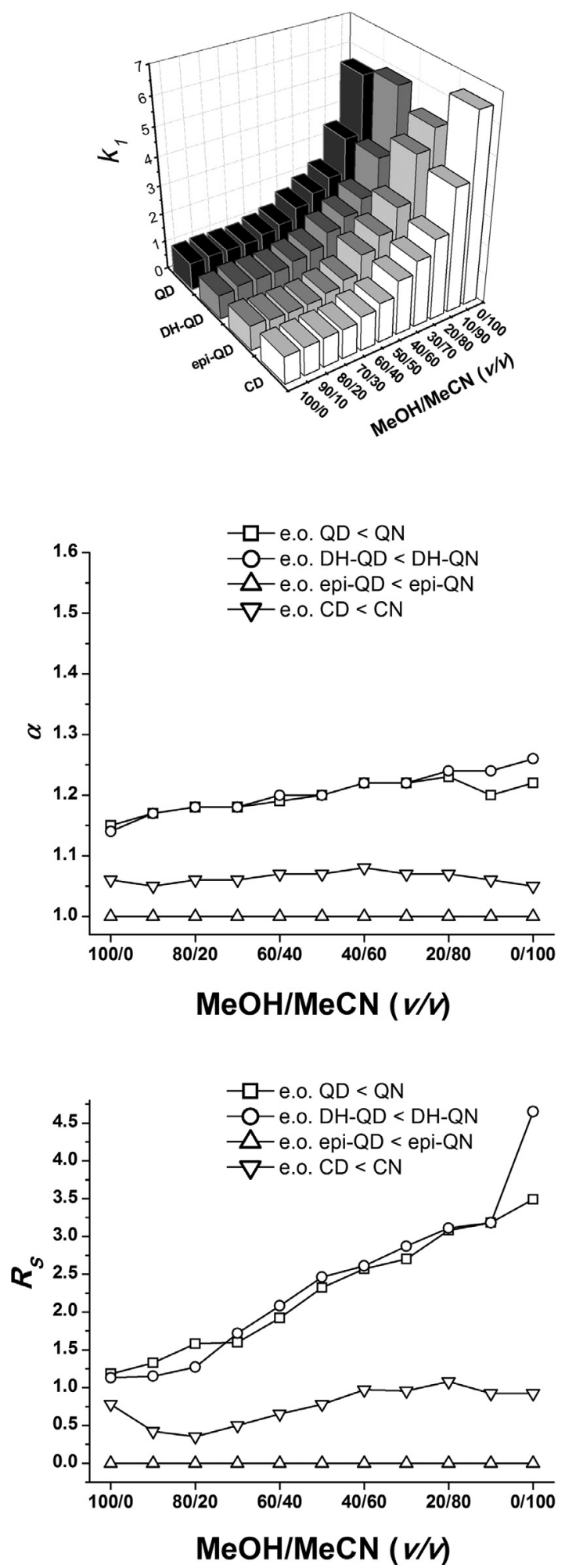

ZWIX(-) $)^{\mathrm{TM}}$
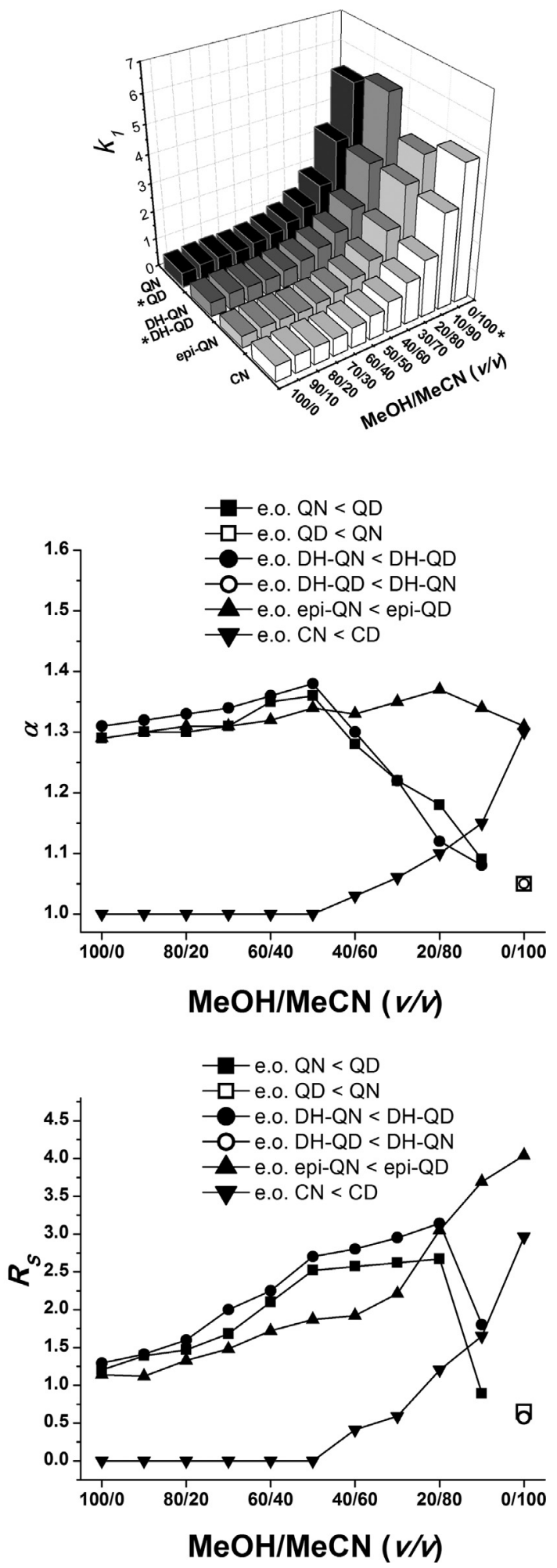

Fig. 3. Influence of mobile phase composition on $k_{1}, \alpha$ and $R_{S}$ of Cinchona alkaloid analogs.

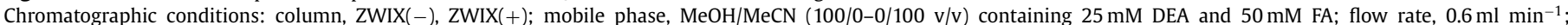

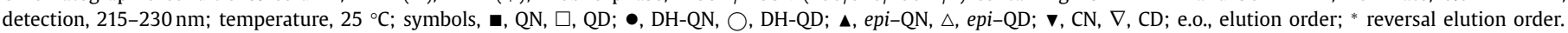



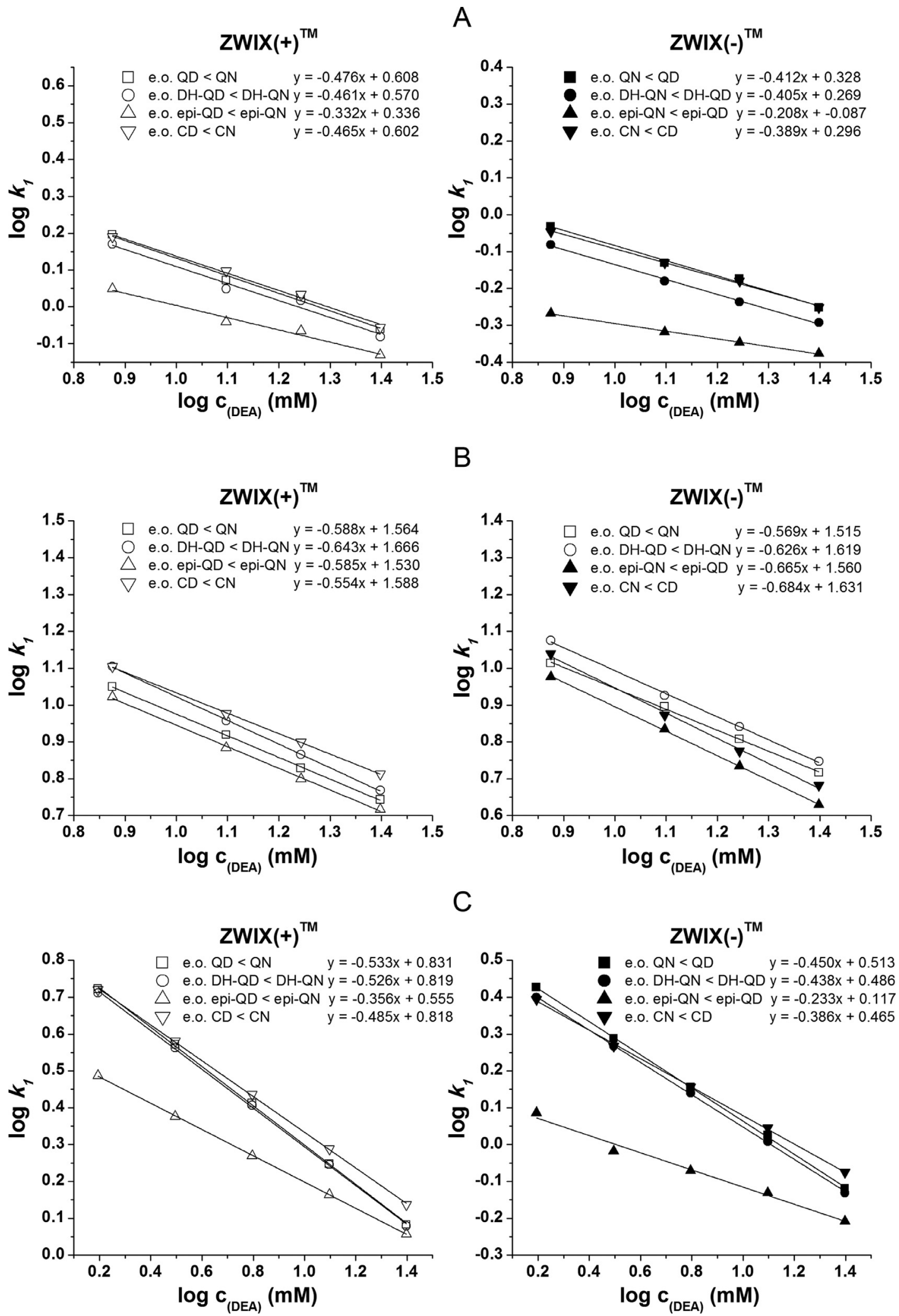

Fig. 4. Influence of the counter-ion concentration on the retention of the first-eluting enantiomer $\left(k_{1}\right)$ for Cinchona alkaloid analogs on ZWIX( + ) and ZWIX(-)

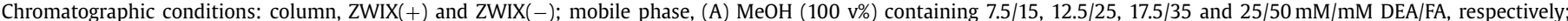

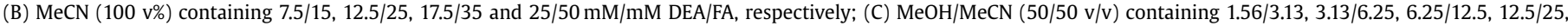

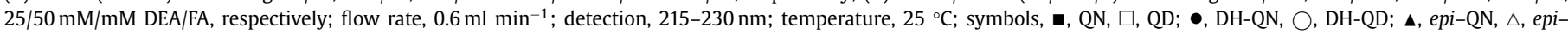
$\mathrm{QD} ; \mathbf{\nabla}, \mathrm{CN}, \nabla, \mathrm{CD}$; e.o., elution order. 
Table 3

Chromatographic data, $k_{1}, k_{2}, \alpha, R_{S}$, plate numbers and elution sequence of Cinchona alkaloid analogs on zwitterionic chiral stationary phases at SFC condition.

\begin{tabular}{|c|c|c|c|c|c|c|c|}
\hline Compound & $k_{1}$ & $k_{2}$ & $\alpha$ & $R_{S}$ & $N_{1}$ & $\mathrm{~N}_{2}$ & Elution order \\
\hline \multicolumn{8}{|c|}{ ZWIX(-) } \\
\hline QN/QD* & 1.83 & 2.36 & 1.29 & 2.74 & 4238 & 3678 & $(-) \mathrm{QN}<(+) \mathrm{QD}$ \\
\hline QN/QD & 7.99 & 9.91 & 1.24 & 4.00 & 6499 & 7310 & $(-) \mathrm{QN}<(+) \mathrm{QD}$ \\
\hline rac. $\mathrm{QN}^{*}$ & 1.83 & 2.24 & 1.22 & 1.90 & 3284 & 3654 & $(-) \mathrm{QN}<(+) \mathrm{QN}$ \\
\hline rac.QN & 7.99 & 9.03 & 1.13 & 2.60 & 7917 & 9211 & $(-) \mathrm{QN}<(+) \mathrm{QN}$ \\
\hline rac. $\mathrm{CF}_{3} \mathrm{PQN}^{*}$ & 2.13 & 2.33 & 1.09 & 0.97 & 7538 & 8606 & n.d. \\
\hline rac. $\mathrm{CF}_{3} \mathrm{PQN}$ & 10.80 & 11.36 & 1.05 & 0.84 & 5750 & 5524 & n.d. \\
\hline DH-QN/DH-QD* & 1.97 & 2.59 & 1.31 & 3.06 & 3786 & 5210 & $(-) \mathrm{DH}-\mathrm{QN}<(+) \mathrm{DH}-\mathrm{QD}$ \\
\hline DH-QN/DH-QD & 7.24 & 9.14 & 1.26 & 4.01 & 5341 & 6901 & $(-) \mathrm{DH}-\mathrm{QN}<(+) \mathrm{DH}-\mathrm{QD}$ \\
\hline ерi-QN/epi-QD* & 7.18 & 9.86 & 1.37 & 3.87 & 3003 & 3041 & $(-)$ epi-QN $<(+)$ epi-QD \\
\hline epi-QN/epi-QD & 33.21 & 42.17 & 1.27 & 4.29 & 5768 & 6724 & $(-)$ epi-QN $<(+) e p i-Q D$ \\
\hline $\mathrm{CD} / \mathrm{CN}^{*}$ & 2.25 & 2.25 & 1.00 & 0.00 & 984 & - & - \\
\hline $\mathrm{CD} / \mathrm{CN}$ & 9.09 & 9.46 & 1.04 & 0.77 & 6606 & 5842 & $\mathrm{CD}<\mathrm{CN}$ \\
\hline \multicolumn{8}{|c|}{$\operatorname{ZWIX}(+)$} \\
\hline QN/QD* & 2.52 & 2.73 & 1.08 & 1.02 & 4250 & 4244 & $(+) \mathrm{QD}<(-) \mathrm{QN}$ \\
\hline $\mathrm{QN} / \mathrm{QD}$ & 10.27 & 10.27 & 1.00 & 0.00 & 6645 & - & - \\
\hline rac. QN* & 2.30 & 2.73 & 1.19 & 2.27 & 5323 & 5079 & $(+) \mathrm{QN}<(-) \mathrm{QN}$ \\
\hline rac.QN & 9.16 & 10.23 & 1.12 & 2.65 & 10724 & 10475 & $(+) \mathrm{QN}<(-) \mathrm{QN}$ \\
\hline rac. $\mathrm{CF}_{3} \mathrm{PQN}^{*}$ & 2.54 & 2.95 & 1.16 & 1.47 & 12485 & 13573 & n.d. \\
\hline rac. $\mathrm{CF}_{3} \mathrm{PQN}$ & 12.33 & 13.16 & 1.07 & 1.25 & 7639 & 7338 & n.d. \\
\hline DH-QN/DH-QD* & 2.39 & 2.58 & 1.08 & 1.01 & 12208 & 14226 & $(+) \mathrm{DH}-\mathrm{QD}<(-) \mathrm{DH}-\mathrm{QN}$ \\
\hline DH-QN/DH-QD & 9.41 & 9.41 & 1.00 & 0.00 & 2061 & - & - \\
\hline epi-QN/epi-QD* & 10.93 & 10.93 & 1.00 & 0.00 & 5020 & - & - \\
\hline ерi-QN/epi-QD & 45.26 & 45.26 & 1.00 & 0.00 & 4813 & - & - \\
\hline $\mathrm{CD} / \mathrm{CN}^{*}$ & 2.77 & 3.11 & 1.12 & 1.38 & 4718 & 3267 & $\mathrm{CD}<\mathrm{CN}$ \\
\hline $\mathrm{CD} / \mathrm{CN}$ & 10.61 & 11.81 & 1.11 & 2.47 & 9401 & 9875 & $\mathrm{CD}<\mathrm{CN}$ \\
\hline
\end{tabular}

Chromatographic conditions: column, ZWIX(-) and ZWIX(+); mobile phase, $\mathrm{CO}_{2} / \mathrm{MeOH}(90 / 10 \mathrm{v} / \mathrm{v})$ or ${ }^{*}(70 / 30 \mathrm{v} / \mathrm{v})$ all containing $25 \mathrm{mM}$ DEA and $50 \mathrm{mM} \mathrm{FA}$; flow rate, $2.0 \mathrm{ml} \mathrm{min}^{-1}$; detection, 215 $230 \mathrm{~nm}$; temperature, $40^{\circ} \mathrm{C}$; back pressure, 150 bar; n.d., not determined; $t_{0}$ : ZWIX(-) $0.44 \mathrm{~min}$, ZWIX $(+)$ $0.43 \mathrm{~min}$.

Table 4

Elution sequence of Cinchona alkaloid analogs on zwitterionic ZWIX(-), ZWIX(-A), ZWIX(+), ZWIX(+A) and on chiral strong cation-exchanger DCl-(S,S), DML- $(S, S), \mathrm{DCl}-(R, R)$ and DML- $(R, R)$ CSPs.

\begin{tabular}{|c|c|c|c|c|c|c|c|}
\hline Chiral core & Sub-units & Columns & QN/QD & rac.QN & $\mathrm{CD} / \mathrm{CN}$ & DH-QN/DH-QD & epi-QN/epi-QD \\
\hline - & $(S, S)$-ACHSA & $\mathrm{DCl}-(S, S)$ & $-) \mathrm{QN}<\mathrm{QD}$ & $-) \mathrm{QN}<(+) \mathrm{QN}$ & $\mathrm{CD}<\mathrm{CN}$ & $(-) \mathrm{DH}-\mathrm{QN}<(+) \mathrm{DH}-\mathrm{QD}$ & - \\
\hline - & -ACHSA & IL- $(S, S)$ & $\mathrm{QN}<$ & $2 \mathrm{~N}<$ & $\mathrm{CD}<\mathrm{CN}$ & DH-QN < (+)DH-QD & - \\
\hline $\mathrm{QN}$ & $(S, S)$-ACHSA & ZWIX $(+)^{\mathrm{TM}}$ & $<(-) \mathrm{QN}$ & $\mathrm{QN}<$ & $\mathrm{CD}<\mathrm{CN}$ & $(+) \mathrm{DH}-\mathrm{QD}<(-) \mathrm{DH}-\mathrm{QN}$ & - \\
\hline$* * \mathrm{QN}$ & $(S, S)$-ACHSA & $\mathrm{ZWIX}(+)^{\mathrm{TM}}$ & $\mathrm{QD}<(-) \mathrm{QN}$ & $(+) \mathrm{QN}<(-) \mathrm{QN}$ & $\mathrm{CD}<\mathrm{CN}$ & $(+) \mathrm{DH}-\mathrm{QD}<(-) \mathrm{DH}-\mathrm{QN}$ & - \\
\hline $\mathrm{QD}$ & $(S, S)$-ACHSA & ZWIX(-A) & $\mathrm{QD}<(-) \mathrm{QN}$ & $(-) \mathrm{QN}<$ & $\mathrm{CN}<\mathrm{CD}$ & $(+)$ DH-QD $<$ & $(+) e p i-\mathrm{QD}<(-) e p i-\mathrm{QN}$ \\
\hline - & $(R, R)$-ACHSA & $\mathrm{DCl}-(R$, & $(-) \mathrm{QN}<\mathrm{QD}$ & $(-) \mathrm{QN}$ & - & $(-) \mathrm{DH}-\mathrm{QN}<($ & $(-) e p$ \\
\hline - & $(R, R)$-ACHSA & DML- $(R, R)$ & $(-) \mathrm{QN}<\mathrm{QD}$ & $(+) \mathrm{QN}<(-) \mathrm{QN}$ & $\mathrm{CD}<\mathrm{CN}$ & $(-) \mathrm{DH}-\mathrm{QN}<(+) \mathrm{DH}-\mathrm{QD}$ & $(-)$ epi-QN $<(+) e p i-\mathrm{QD}$ \\
\hline $\mathrm{QL}$ & $(R, R)$-ACHSA & ZWIX(- $)^{\mathrm{TM}}$ & $(-) \mathrm{QN}<\mathrm{QD}$ & $(-) \mathrm{QN}<(+) \mathrm{QN}$ & ${ }^{*} \mathrm{CN}<\mathrm{CD}$ & $(-)$ DH-QN $<(+)$ DH-QD & ${ }^{*}(-)$ epi-QN $<(+)$ epi-QD \\
\hline$* * \mathrm{QD}$ & $(R, R)$-ACHSA & ZWIX(- $)^{\mathrm{TM}}$ & $(-) Q N<Q D$ & $(-) \mathrm{QN}$ & $\mathrm{CD}<\mathrm{CN}$ & $(-) \mathrm{DH}-\mathrm{QN}<(+) \mathrm{DH}-\mathrm{QD}$ & $(-) e p i-\mathrm{QN}<(+)$ epi-QD \\
\hline QN & $(R, R)-\mathrm{ACHSA}$ & $\mathrm{ZWIX}(+\mathrm{A})$ & $\mathrm{QD}<(-) \mathrm{QN}$ & $(+) \mathrm{QN}<(-) \mathrm{QN}$ & $\mathrm{CN}<\mathrm{CD}$ & $(+) \mathrm{DH}-\mathrm{QD}<(-) \mathrm{DH}-\mathrm{QN}$ & $(-) e p i-\mathrm{QN}<(+) e p i-\mathrm{QD}$ \\
\hline
\end{tabular}

Chromatographic conditions: columns, ZWIX(-), ZWIX(-A), ZWIX(+), ZWIX(+A), DCl-(S,S), DML-(S,S), DCl-(R,R) and DML- $(R, R)$; mobile phase, on zwitterionic phases, in PIM MeOH/MeCN (50/50 v/v) containing $25 \mathrm{mM} \mathrm{DEA}$ and $50 \mathrm{mM} \mathrm{FA,}{ }^{*} \mathrm{MeOH} / \mathrm{MeCN}(10 / 90 \mathrm{v} / \mathrm{v})$ containing $25 \mathrm{mM}$ DEA and $50 \mathrm{mM}$ FA, ${ }^{* *}$ at SFC condition $\mathrm{CO}_{2} / \mathrm{MeOH}(90 / 10 \mathrm{v} / \mathrm{v})$ containing $25 \mathrm{mM}$ DEA and $50 \mathrm{mM}$ FA and on strong ion-exchanger phases, $\mathrm{MeOH}$ containing $37.5 \mathrm{mM} \mathrm{NH} 4 \mathrm{OAc}$; flow

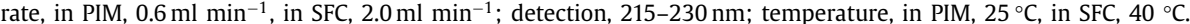

fusion with QN leads to a fully changed spatial arrangement of the molecular residues around the stereoselective binding grove.

For the resolution of the diastereomeric pairs QN/QD, $\mathrm{DHQN} / \mathrm{DHQD}, \mathrm{CD} / \mathrm{CN}$, and epi-QN/epi-QD, such a clear trend cannot be seen. On both $(R, R)$ - and $(S, S)$-ACHSA-based cSCX columns the elution sequence $\mathrm{QN}<\mathrm{QD}, \mathrm{DHQN}<\mathrm{DHQD}$, and $\mathrm{CD}<\mathrm{CN}$ remains, as a clear indication of the difficulty to interpret enantioselectivity versus diastereoselectivity. The situation becomes even more complicated when studying chiral selector motifs with multi-chiral centers, such as ZWIX $(-) / Z W I X(-A)$ and ZWIX $(+) / Z W I X(+A)$ CSPs. (See an example of the chromatographic resolution of $\mathrm{CD} / \mathrm{CN}$ in Fig. S1.).
Unexpected reversals of elution order of the diastereomeric (pseudo-enantiomer) pairs can easily happen as a function of the diastereomeric chiral selector motifs per se, but also as a function of the bulk solvent composition of the mobile phase, as can be seen in Figs. 3 and 4.

In this context, it became particularly interesting that under LC conditions the elution orders of $\mathrm{CN}<\mathrm{CD}$ changed in SFC modality to $\mathrm{CD}<\mathrm{CN}$ on the $\mathrm{ZWIX}(-)$ column (Table 4). It is another strong indication for the role of solvation on the overall diastereoselectivity. As an essential part of this discussion, the conformational aspects of the selector moieties need also to be taken into account. It is also necessary for the so-called anti-open 
A

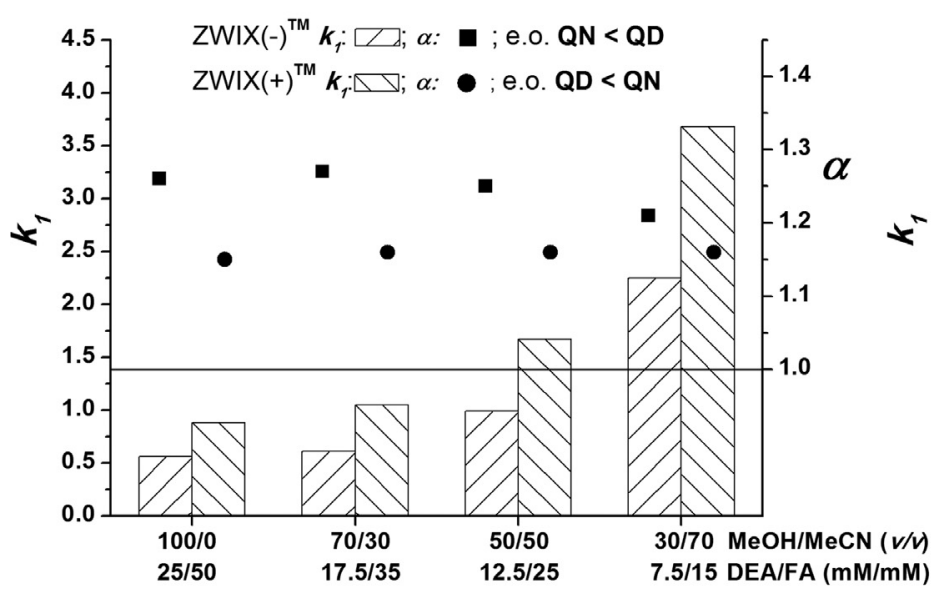

C

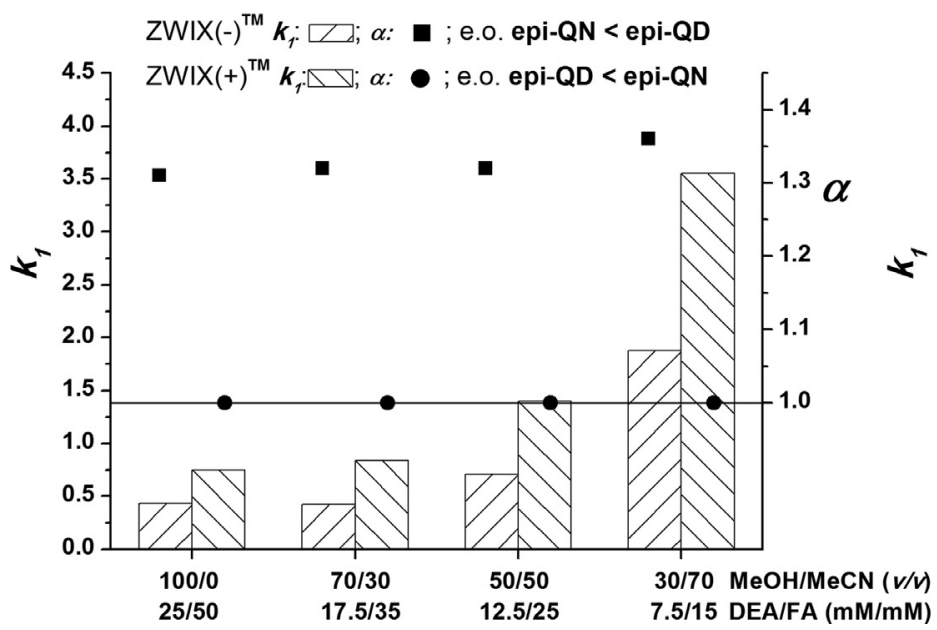

B

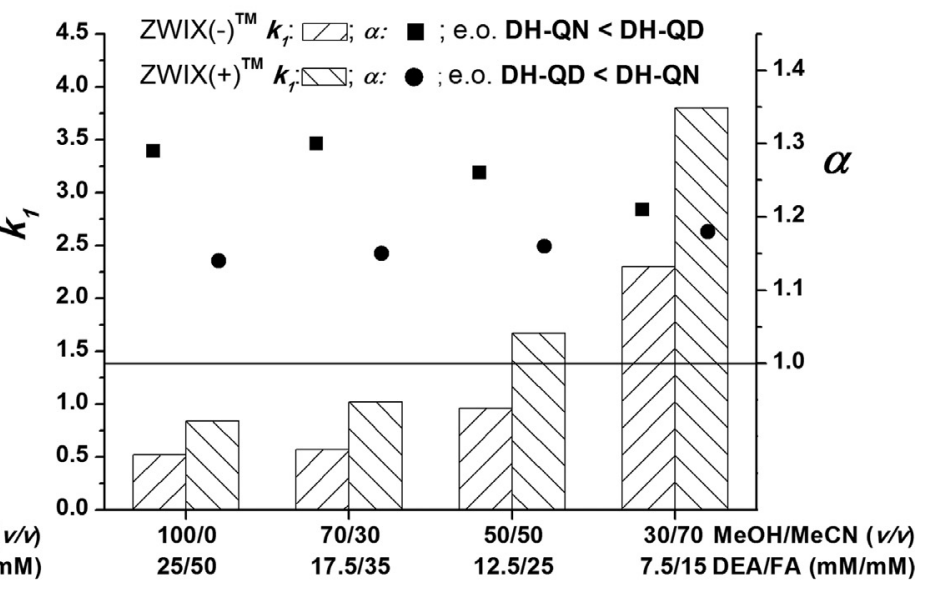

D

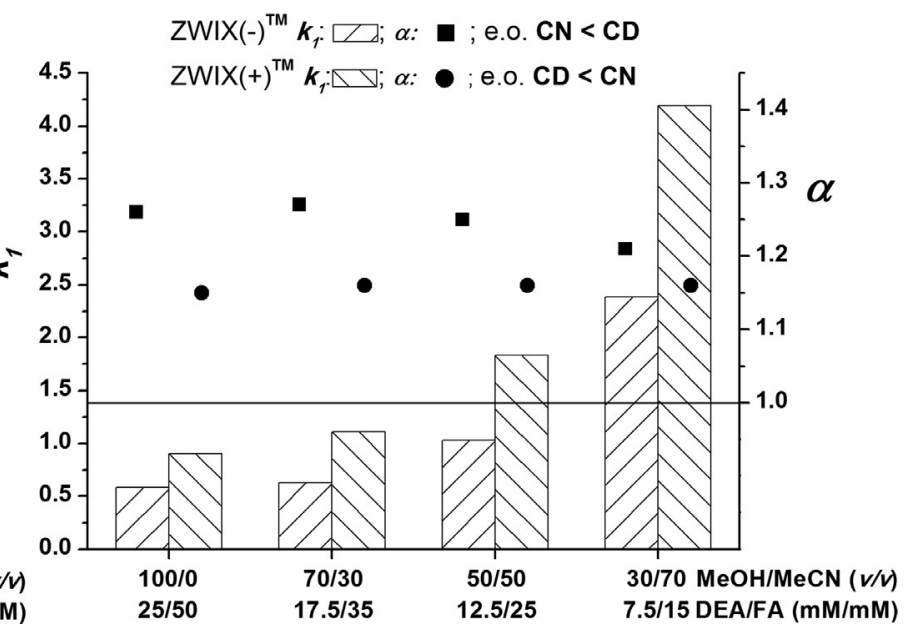

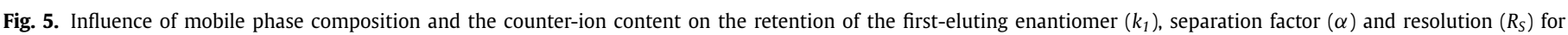
Cinchona alkaloid analogs on $\mathrm{ZWIX}(+)$ and $\mathrm{ZWIX}(-)$.

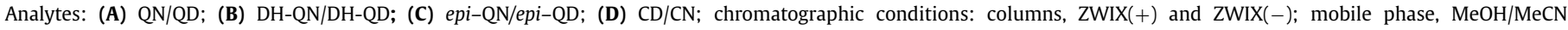

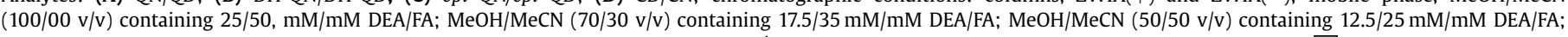

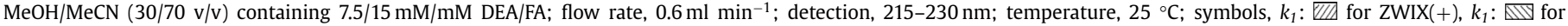
$\mathrm{ZWIX}(-) ; \alpha: \bullet$ for $\mathrm{ZWIX}(+), \alpha$ : $\boldsymbol{\bullet}$ for $\operatorname{ZWIX}(-)$.

conformational behavior of the QN moiety under acidic conditions, the one having the highest probability [31,32]. However, minor conformers may also exist, which will certainly affect the overall stereoselectivity performance of such type of motifs as of the ZWIX selectors and phase.

\subsection{Enantiomer and diastereomer separations of a set of Cinchona alkaloid analogues}

In the section above, results of a set of several systematic investigations were summarized in Tables, Figures, and in the Supporting Material. On the basis of these data, it becomes obvious that the enantiomer resolution of the novel racemic quinine $( \pm \mathrm{QN})$ and of its racemic analogues $\left[( \pm) \mathrm{CF}_{3} \mathrm{PQN}\right]$ is straightforward and works essentially on all eight investigated cation-exchangers, whereby four of them have zwitterionic character (Tables 1 and 2). The expected reversal of elution order of the enantiomers is evident for the (S,S)-ACHSA- and $(R, R)$-ACHSA-based cSCX columns. The same sequence occurs for the QD-(S,S)-ACHSA type ZWIX(-A) and $\mathrm{QN}-(R, R)$-ACHSA type $\mathrm{ZWIX}(+\mathrm{A})$ columns.
However, the combination of the chiral subunits of $\mathrm{QN}$ and $(S, S)$-ACHSA, which relate to the ZWIX(+) column, and the one of $\mathrm{QD}$ and $(R, R)$-ACHSA relating to $\mathrm{ZWIX}(-)$, show a reversed enantioselectivity, but still behaving pseudo-enantiomerically to each other.

The effects of bulk solvent composition and counter-ion concentration on the retention and diastereoselective characteristics of four Cinchona alkaloid analogues on the ZWIX(+) and ZWIX(-) columns are presented in Fig. 5 and in Table S3. The $\alpha$ values of four pairs stay relatively constant, whereas the retention data change progressively with the dilution of the organic salt and acid additives in the mobile phase.

Representative chromatograms for the resolution of racemic quinine on the ZWIX(+) and ZWIX(-) columns in LC and SFC mode are depicted in Fig. 6, corroborating the potential of zwitterionic ion-exchangers used as chiral cation-exchanger. Similar useful columns are the chiral strong cation-exchangers for the separation of the diverse natural and synthetic Cinchona alkaloid analogues exemplified by Fig. S2. Both peak symmetries and efficiencies of the columns are very reasonable. Additional chromatographic 


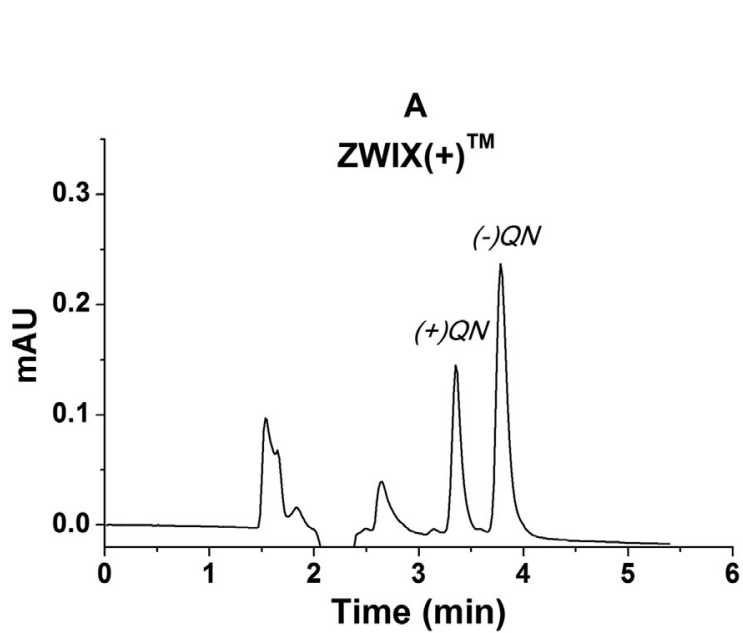

\section{PIM}

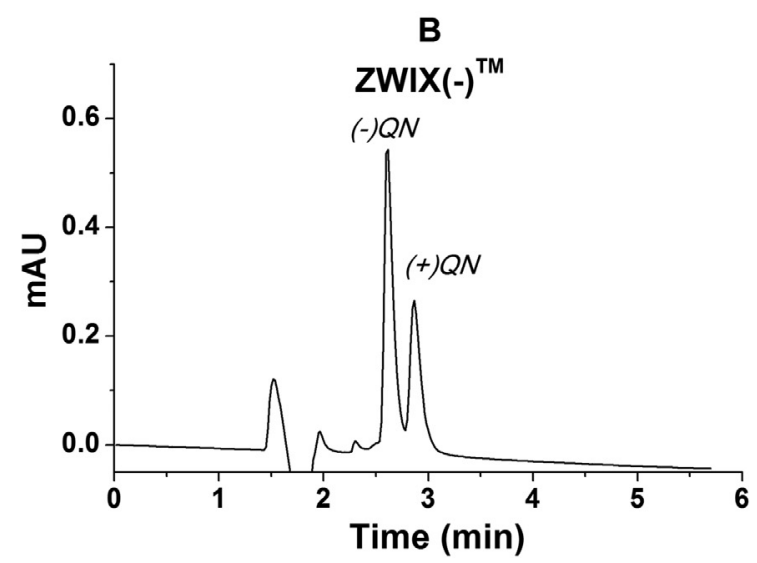

\section{SFC}
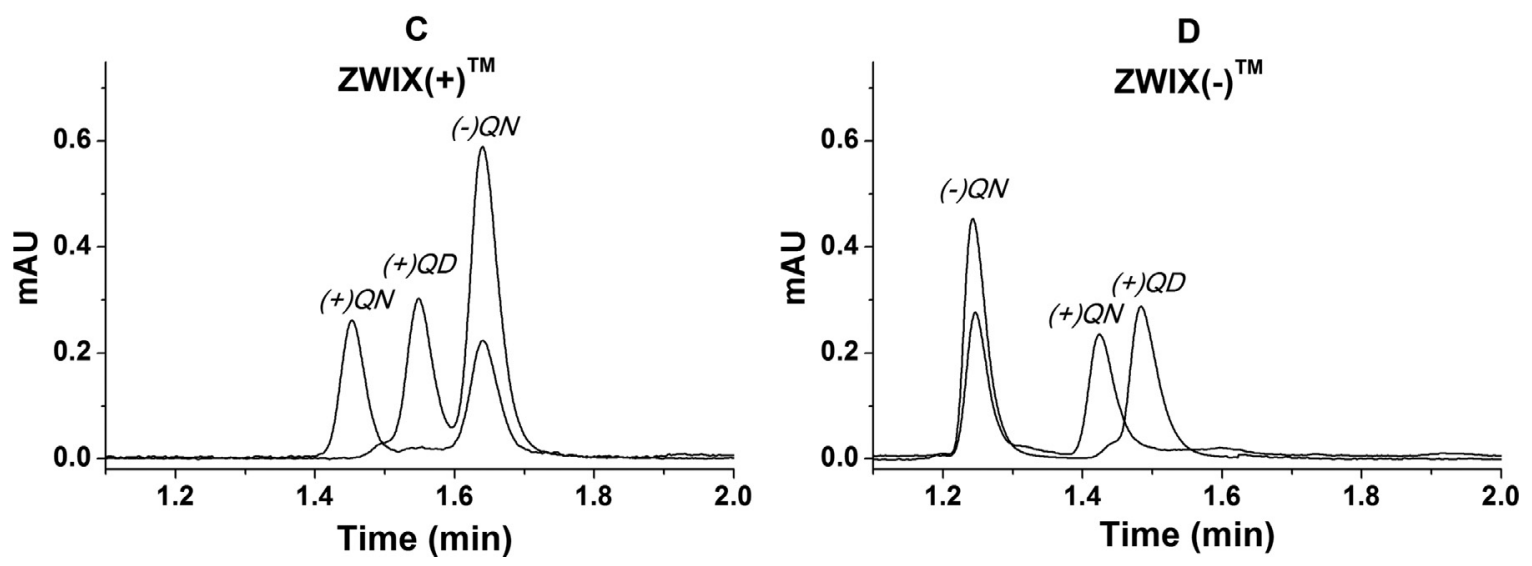

Fig. 6. Chromatograms indicating elution order for rac.QN stereoisomers on ZWIX(+) and ZWIX(-) CSPs in PIM and SFC techniques.

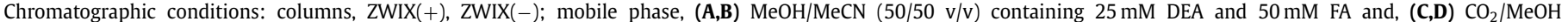
$(70 / 30 \mathrm{v} / \mathrm{v})$ containing $25 \mathrm{mM}$ DEA and $50 \mathrm{mM} \mathrm{FA}$; flow rate, in PIM, $0.6 \mathrm{ml} \mathrm{min}^{-1}$, in SFC, $2.0 \mathrm{ml} \mathrm{min}^{-1}$; detection, $215-230 \mathrm{~nm}$; temperature, in PIM, $25{ }^{\circ} \mathrm{C}$, in SFC, $40{ }^{\circ} \mathrm{C}$.

results (as the basis of data interpretation) can be found in the Supplementary Information (Figs. S3-S9).

\section{Conclusions}

In this comprehensive study we have demonstrated the use of chiral strong cation-exchangers and chiral zwitterionic ionexchangers for the separation of natural and synthetic Cinchona alkaloid analogues. Additional possibilities to trigger the stereoselective retention and separation characteristics, including the reversal of elution orders have been described. It is important to emphasize that these possibilities cannot be reached by non-chiral stationary phases employed in reversed phase, normal phase or SFC mode [1]. Usually, the elution sequence $\mathrm{QD}<\mathrm{QN}, \mathrm{DHQD}<\mathrm{DHQN}$, epi-QD $<$ epi-QN, and $\mathrm{CN}<\mathrm{CD}$ remains fixed, whereas with the employment of the eight, somewhat related ionic CSPs and "chiral columns" thereof, described here, the sequences can be reversed.

Particular interest has been focused on the observed enantioselectivity of these CSPs for the resolution of the very unique and only recently described racemic quinine samples [5]. All investigated chiral ion-exchange type columns are characterized by excellent efficiency and high flexibility to adjust the retention times of the basic analytes via the mobile phase composition, e.g., by varying the type of bulk solvents used and the concentration of the organic salt additives. A central part of this study relates also to the evaluation and discussion of the molecular parameter and structural motifs of the chiral selectors influencing the retention characteristics in the light of molecular recognition phenomena.

This study demonstrates the principal use of appropriate chiral cation ion-exchangers and chiral zwitterionic phases working as CSCX type stationary phases for liquid chromatography of basic analytes with mobile phase conditions, compatible with LC-MS/MS applications. This includes also the straightforward application of SFC with liquid $\mathrm{CO}_{2}$ in combination with protic solvents under subcritical conditions.

\section{Declaration of Competing Interest}

Authors declare no conflict of interest.

\section{Acknowledgments}

This work was supported by the project grant GINOP-2.3.215-2016-00034. The Ministry of Human Capacities, Hungary grant 20391-3/2018/FEKUSTRAT is also acknowledged. The authors thank in particular Prof. Nuno Maulide for providing the samples of the racemic quinine analogues. Prof. Michal Kohout and Dr. Denise Wolrab are gratefully acknowledged for providing the four strong cation-exchangers and the $\mathrm{ZWIX}(+\mathrm{A})$ and $\mathrm{ZWIX}(-\mathrm{A})$ columns. The 
ZWIX $(+)$ and ZWIX(-) columns have been provided by Dr. Pilar Franco and Chiral Technologies Europe, for which we are thankful.

\section{Supplementary materials}

Supplementary material associated with this article can be found, in the online version, at doi:10.1016/j.chroma.2019.460498.

\section{References}

[1] D.V. McCalley, Analysis of the Cinchona alkaloids by high-performance liquid chromatography and other separation techniques, J. Chromatogr. A 967 (2002) 1-19, doi:10.1016/S0021-9673(01)01557-6.

[2] A. Murauer, M. Ganzera, Quantitative determination of major alkaloids in Cinchona bark by Supercritical Fluid Chromatography, J. Chromatogr. A 1554 (2018) 117-122, doi:10.1016/j.chroma.2018.04.038.

[3] C.V. Hoffmann, M. Lämmerhofer, W. Lindner, Separation of Cinchona alkaloids on a novel strong cation-exchange-type chiral stationary phase-comparison with commercially available strong cation exchanger and reversed-phase packing materials, Anal. Bioanal. Chem. 393 (2009) 1257-1265, doi:10.1007| s00216-008-2557-z.

[4] L. Lee, D.Y.K. Chen, A Local-desymmetrization-based divergent synthesis of quinine and quinidine, Angew. Chem. 131 (2019) 498-503, doi:10.1002/ange. 201811530.

[5] D.H. O' Donovan, P. Aillard, M. Berger, A. de la Torre, D. Petkova, C. KnittlFrank, D. Geerdink, M. Kaiser, N. Maulide, C-H Activation enables a concise total synthesis of quinine and analogues with enhanced antimalarial activity, Angew. Chem. Int. Ed. 57 (2018) 10737-10741, doi:10.1002/anie.201804551.

[6] N.M. Mayer, L. Nicoletti, M. Lämmerhofer, W. Lindner, Enantioselective anion exchangers based on cinchona alkaloid-derived carbamates: influence of C8/C9 stereochemistry on chiral recognition, Chirality 11 (1999) 522-528, doi:10.1002/(SICI)1520-636X(1999)11:7〈522::AID-CHIR2〉3.0.CO;2-U.

[7] W. Liu, W. Qin, X. Wang, F. Xue, X.-Y. Liu, Y. Qin, Bioinspired synthesis of (+)Cinchonidine using cascade reactions, Angew. Chem. 130 (2018) 12479-12482, doi:10.1002/ange.201804848.

[8] M. Lammerhofer, Chiral recognition by enantioselective liquid chromatography: mechanisms and modern chiral stationary phases, J. Chromatogr. A 1217 (2010) 814-856, doi:10.1016/j.chroma.2009.10.022.

[9] Y. Liu, K. Hoshina, J. Haginaka, Monodispersed, molecularly imprinted polymers for cinchonidine by precipitation polymerization, Talanta 80 (2010) 1713 1718, doi:10.1016/j.talanta.2009.10.011.

[10] J. Haginaka, C. Kagawa, Highly stereoselective, uniformly sized molecularly imprinted polymers for Cinchona alkaloids in hydro-organic mobile phases, Anal. Sci. 19 (2003) 39-42, doi:10.2116/analsci.19.39.

[11] B. Chankvetadze, Recent developments on polysaccharide-based chiral stationary phases for liquid-phase separation of enantiomers, J. Chromatogr. A 1269 (2012) 26-51, doi:10.1016/j.chroma.2012.10.033.

[12] E. Lipka, A.E. Dascalu, Y. Messera, E. Tsutsqiridze, T. Farkas, B. Chankvetadze, Separations of enantiomers of native amino acids with polysaccharide-based chiral columns in supercritical fluid chromatography, J. Chromatogr. A 1585 (2019) 207-212, doi:10.1016/j.chroma.2018.11.049.

[13] D. Albals, Y.V. Heyden, M.G. Schmid, B. Chankvetadze, D. Mangelings, Chiral separations of cathinone and amphetamine-derivatives: comparative study between capillary electrochromatography, supercritical fluid chromatography and three liquid chromatographic modes, J. Pharmaceut. Biomed. 121 (2016) 232243, doi:10.1016/j.jpba.2015.12.007.

[14] R. Franzini, A. Ciogli, F. Gasparrini, O.H. Ismail, C. Villani, Recent developments in chiral separations by supercritical fluid chromatography, in: P.L. Polavarapu (Ed.), Chiral Analysis: Advances in Spectroscopy, Chromatography and Emerging Methods, Vanderbilt University, Nashville, 2018, pp. 607-629, doi:10.1016/ B978-0-444-64027-7.00016-1.

[15] O.H. Ismail, S. Felletti, C.D. Luca, L. Pasti, N. Marchetti, V. Costa, F. Gasparrini, A. Cavazzini, M. Catani, The way to ultrafast, high-throughput enantioseparations of bioactive compounds in liquid and supercritical fluid chromatography, Molecules 23 (2018) 2709, doi:10.3390/molecules23102709.

[16] O.H. Ismail, M. Antonelli, A. Ciogli, C. Villani, A. Cavazzini, M. Catani, S. Felletti, D.S. Bell, F. Gasparrini, Future perspectives in high efficient and ultrafast chiral liquid chromatography through zwitterionic teicoplanin-based 2- $\mu \mathrm{m}$ superficially porous particles, J. Chromatogr. A 1520 (2017) 91-102, doi:10.1016/ j.chroma.2017.09.008.

[17] C.V. Hoffmann, R. Pell, M. Lämmerhofer, W. Lindner, Synergistic effects on enantioselectivity of zwitterionic chiral stationary phases for separations of chiral acids, bases, and amino acids by HPLC, Anal. Chem. 80 (2008) 87808789, doi:10.1021/ac801384f.

[18] S. Wernisch, R. Pell, W. Lindner, Increments to chiral recognition facilitating enantiomer separations of chiral acids, bases, and ampholytes using Cinchonabased zwitterion exchanger chiral stationary phases, J. Sep. Sci. 35 (2012) 1560-1572, doi:10.1002/jssc.201200103.

[19] F. Ianni, Z. Pataj, H. Gross, R. Sardella, B. Natalini, W. Lindner, M. Lämmerhofer, Direct enantioseparation of underivatized aliphatic 3-hydroxyalkanoic acids with a quinine-based zwitterionic chiral stationary phase, J. Chromatogr. A 1363 (2014) 101-108, doi:10.1016/j.chroma.2014.03.060.

[20] N. Grecsó, M. Kohout, A. Carotti, R. Sardella, B. Natalini, F. Fülöp, W. Lindner, A. Péter, I. Ilisz, Mechanistic considerations of enantiorecognition on novel Cinchona alkaloid-based zwitterionic chiral stationary phases from the aspect of the separation of trans-paroxetine enantiomers as model compounds, J. Pharm. Biomed. 124 (2016) 164-173, doi:10.1016/j.jpba.2016.02.043.

[21] I. Ilisz, N. Grecsó, A. Aranyi, P. Suchotin, D. Tymecka, B. Wilenska, A. Misicka, F. Fülöp, W. Lindner, A. Péter, Enantioseparation of $\beta^{2}$-amino acids on cinchona alkaloid-based zwitterionic chiral stationary phases. Structural and temperature effects, J. Chromatogr. A 1334 (2014) 44-54, doi:10.1016/j.chroma.2014.01. 075.

[22] I. Ilisz, Z. Gecse, Z. Pataj, F. Fülöp, G. Tóth, W. Lindner, A. Péter, Direct highperformance liquid chromatographic enantioseparation of secondary amino acids on Cinchona alkaloid-based chiral zwitterionic stationary phases. Unusual temperature behavior, J. Chromatogr. A 1363 (2014) 169-177, doi:10.1016/j. chroma.2014.06.087.

[23] I. Ilisz, N. Grecsó, R. Papoušek, Z. Pataj, P. Barták, L. Lázár, F. Fülöp, W. Lindner, A. Péter, High-performance liquid chromatographic separation of unusual $\beta^{3}$-amino acid enantiomers in different chromatographic modes on Cinchona alkaloid-based zwitterionic chiral stationary phases, Amino Acids 47 (2015) 2279-2291, doi:10.1007/s00726-015-2006-1.

[24] N. Grecsó, E. Forró, F. Fülöp, A. Péter, I. Ilisz, W. Lindner, Combinatorial effects of the configuration of the cationic and the anionic chiral subunits of four zwitterionic chiral stationary phases leading to reversal of elution order of cyclic $\beta^{3}$-amino acid enantiomers as ampholitic model compounds, J. Chromatogr. A 1467 (2016) 178-187, doi:10.1016/j.chroma.2016.05.041.

[25] S. Wernisch, W. Lindner, Versatility of cinchona-based zwitterionic chiral stationary phases: Enantiomer and diastereomer separations of non-protected oligopeptides utilizing a multi-modal chiral recognition mechanism, J. Chromatogr. A 1269 (2012) 297-307, doi:10.1016/j.chroma.2012.06.094.

[26] D. Wolrab, P. Frühauf, M. Kohout, W. Lindner Click chemistry immobilization strategies in the development of strong cation exchanger chiral stationary phases for HPLC, J. Sep. Sci. 36 (2013) 2826-2837, doi:10.1002/jssc.201300559.

[27] T. Zhang, E. Holder, P. Franco, W. Lindner, Method development and optimization on cinchona and chiral sulfonic acid-based zwitterionic stationary phases for enantiomer separations of free amino acids by high-performance liquid chromatography, J. Chromatogr. A 1363 (2014) 191-199, doi:10.1016/j.chroma. 2014.06.012.

[28] W. Kopaciewicz, M.A. Rounds, J. Fausnaugh, F.E. Regnier, Retention model for high-performance ion-exchange chromatography, J. Chromatogr 266 (1983) 321, doi:10.1016/S0021-9673(01)90875-1.

[29] A. Bajtai, G. Lajkó, I. Szatmári, F. Fülöp, W. Lindner, I Ilisz, A Péter, Dedicated comparisons of diverse polysaccharide- and zwitterionic Cinchona alkaloidbased chiral stationary phases probed with basic and ampholytic indole analogs in liquid and subcritical fluid chromatography mode, J. Chromatogr. A 1563 (2018) 180-190, doi:10.1016/j.chroma.2018.05.064.

[30] D. Wolrab, P. Frühauf, C. Gerner, M. Kohout, W. Lindner, Consequences of transition from liquid chromatography to suprcritical fluid chromatography on the overall performance of a chiral zwitterionic ion-exchanger, J. Chromatogr. A 1517 (2017) 165-175, doi:10.1016/j.chroma.2017.08.022.

[31] H. Caner, P.U. Biedermann, I. Agranat, Conformational spaces of Cinchona alkaloids, Chirality 15 (2003) 637-645, doi:10.1002/chir.10265.

[32] A. Urakaea, D.M. Meier, H. Rüegger, A. Baiker, Conformational behavior of Cinchonidine revisited: A combined theoretical and experimental study, J. Phys. Chem. A 112 (2008) 7250-7255, doi:10.1021/jp803185j. 